\title{
Organization of Individual Afferent Axons in Layer IV of Striate Cortex in a Primate
}

\author{
S. L. Florence and V. A. Casagrande \\ Departments of Cell Biology and Psychology, Vanderbilt University, Nashville, Tennessee 37232
}

Evidence from a number of anatomical and physiological studies shows that information is transmitted from the retina to visual cortex via physiologically and anatomically distinct populations of neurons in the lateral geniculate nucleus (LGN). In order to gain a better understanding of the functional roles of these parallel channels from the LGN to cortex in primates, individual afferent axons to layer IV of striate cortex of galagos were filled with HRP by bulk injection into the white matter underlying striate cortex. A total of 55 axons and their terminal arbors, from zones representing both the central and peripheral visual fields, were completely reconstructed through serial sections. Based upon the sublaminar distribution and the morphology of these axons, they have been categorized into 2 groups, designated type I and II axons. Evidence from both past work and the present study suggests that type I axons represent the projections from physiologically defined $Y$-like ceils in the magnocellular layers of the LGN, while type II axons represent the projections from $X$-like cells in the parvocellular LGN layers. Our results show that type I (presumed $Y$-like) arbors occupy relatively more cortical space within their main terminal sublayer (IV $\alpha$ ) than is the case for the type II (presumed X-like) arbors which ramify primarily in layer IV $\beta$. In addition, type I arbors have larger parent axons, fewer boutons along a restricted length of axon, and a greater tendency to branch in layer VI than type II arbors. Finally, both axon types are larger in the area of cortex representing central vision than in the area representing peripheral vision. These morphological characteristics suggest that the physiological differences between magnocellular and parvocellular geniculate cells may be amplified in cortex by differences in the organization of their terminal arbors. Further, within each afferent population, the terminal organization of axons reflects their visuotopic relationships in striate cortex. Comparison of these findings with data from cats and monkeys supports the idea that the relationship between the size of the terminal arbors of LGN $X$-like or parvocellular cells and the size of the cortical spa-

Received Dec. 1, 1986; revised May 26, 1987; accepted June 3, 1987.

This research was supported by MH0882702 (S.L.F.), EY01778 (V.A.C.), and K04-EY00223 (V.A.C.). We thank Drs. Jon Kaas, George Condo, Preston Garraghty, and James Hutchins for helpful comments on the manuscript, and Dr. Jim McKanna for generously allowing the use of his Bioquant Image Analysis system. We also thank Aurora Buck, Lisa Bruno, Sheila Marvin, Dr, Lance Durden, and Julie Mavity for invaluable technical assistance. Finally, we thank Vera Henley Murphy for typing the manuscript.

Correspondence should be addressed to Dr. Vivien A. Casagrande at the above address.

Copyright (C) 1987 Society for Neuroscience $0270-6474 / 87 / 123850-19 \$ 02.00 / 0$ tial subunit varies with differences in visual acuity across species; for LGN Y-Ilke (or magnocellular) cells this relationship remains constant.

In primates, visual information essential for pattern perception is transmitted from cells of the lateral geniculate nucleus (LGN) to striate cortex. Evidence from a number of anatomical and physiological studies suggests that input to striate cortex arrives from LGN cells with distinct properties. For example, in the LGN of galagos, there are 2 magnocellular layers composed of cells that can be distinguished anatomically by their large cell bodies, widely radiating dendrites, and projections to the upper tier of layer IV of striate cortex (Glendenning et al., 1976; Casagrande and Skeen, 1980; Casagrande and DeBruyn, 1982; Conley et al., 1985; Diamond et al., 1985). Physiologically, these cells possess $\mathrm{Y}$-like properties, including overall high contrast sensitivity, low acuity, and sensitivity to rapid movement (Norton and Casagrande, 1982; Casagrande et al., 1986; Norton et al., 1988). In contrast, smaller cells in the 2 parvocellular layers exhibit a restricted pattern of dendritic arborization (Conley et al., 1985) and their axons ramify in the lower tier of layer IV of striate cortex (Glendenning et al., 1976; Casagrande and Skeen, 1980; Casagrande and DeBruyn, 1982; Diamond et al., 1985). Physiologically, these cells have X-like properties, including poor contrast sensitivity, high acuity, and insensitivity to rapid movement (Norton and Casagrande, 1982; Casagrande et al., 1986; Norton et al., 1988). Finally, the remaining 2 LGN layers, the koniocellular layers, contain a population of very small cells. The morphology of these cells is heterogeneous, they have W-like physiological responses, and they project to layers I and III of striate cortex (Casagrande and DeBruyn, 1982; Norton and Casagrande, 1982; Conley et al., 1985; Diamond et al., 1985; Casagrande et al., 1986; Irvin et al., 1986; Norton et al., 1988). Thus, in galagos, parallel streams of visual information are translated to visual cortex from 3 separate pairs of geniculate layers and, in cortex, remain segregated in separate cortical layers or sublayers. Furthermore, from studies in cats and monkeys where parallel channels or "streams" of information have also been reported (for reviews, see Stone et al., 1979; Lennie, 1980; Stone and Dreher, 1982), it appears that the functional properties of cells in the various cortical layers or sublayers receiving LGN input are different from each other (Hubel and Wiesel, 1962, 1968, 1977; Blasdel and Fitzpatrick, 1984) and, in monkeys, the intracortical connections of these layers and sublayers are distinct (Blasdel et al., 1985; Fitzpatrick et al., 1985). Therefore, parallel channels of information apparently are maintained even in cortex. However, because of the complexity of cortical receptive fields, it is difficult to distinguish the individual con- 
tributions of separate geniculostriate channels. One way to approach this question has been to study the structural organization of geniculostriate afferents. In both cats and monkeys, afferents from the different LGN layers are structurally unique. For example, the axons and terminal arbors of LGN X (or $\mathrm{X}$-like) cells are small compared to the much larger axons and arbors of LGN Y (or Y-like) cells (Bullier and Henry, 1979; Gilbert and Wiesel, 1979; Blasdel and Lund, 1983; Freund et al., 1985; Humphrey et al., 1985). However, because the 2 afferent populations overlap in striate cortex of cats, it is difficult to interpret how each axon population contributes to the receptive fields of cortical neurons. In monkeys, although the afferents are restricted to sublaycrs of cortical laycr IVC, only a limited sample of each axon type has been examined, so it is unclear how the population varies in terms of visual field location. Such information is essential to understanding the function of visual cortex in primates, in which the visual field undergoes tremendous magnification in the area related to central vision.

In the present study we sought to gain a more detailed and complete picture of the variation in LGN axonal morphology in primates, in relationship to both LGN physiology and visual field organization in striate cortex. A preliminary report of some of these data has appeared previously (Florence et al., 1983).

\section{Materials and Methods}

A total of 15 galagos were used for this study, including 4 greater galagos (Galago crassicaudatus argentatus) and 11 lesser galagos (G. senegalensis senegalensis). All animals were either purchased commercially or were born in our breeding colony.

The experimental approach was to label individual geniculostriate axons. This was done by placing HRP in the white matter near the striate cortex (area 17). HRP diffuses into the cut ends of axons and dendrites and results in a Golgi-like filling of individual processes near the injection site. Details of the methods used during the course of these experiments are described below.

Surgery. Animals were deeply anesthetized with ketamine hydrochloride ( $35 \mathrm{mg} / \mathrm{kg}$ initial dose) and firmly secured in a stereotaxic headholder. Surgical levels of anesthesia were maintained throughout the experiment by giving supplemental doses of ketamine hydrochloride as needed. The head was shaved and a skin incision was made over the sagittal sinus. Large bilateral craniotomies were made over the occipital lobes in both hemispheres to expose cortex.

Several methods of administering HRP were used, including (1) placing pellets of dried HRP (Boehringer, type IX) in the white matter and (2) making pressure injections with a Hamilton syringe equipped with a 30-gauge needle. However, the most successful technique was (3) iontophoresis of $20 \% \mathrm{HRP}$ in saline into the white matter with a glass micropipette $(60 \mu$ tip).

$\Lambda$ fter completion of the HRP injections, the skull wounds were covered with Gelfoam soaked in saline, and the muscle and skin were closed over the skull. While the animal recovered from the anesthetic, it was kept on a heating pad and watched carefully to ensure that it was as comfortable as possible. Animals survived $12-18 \mathrm{hr}$ before sacrifice, at which time they were deeply anesthetized with Nembutal $(20 \mathrm{mg} / \mathrm{kg})$ and perfused transcardially with a saline rinse followed by a glutaraldehyde fixative.

Histological processing. The freshly fixed visual cortices were cut frozen on a sliding microtome in either the frontal or parasagittal planes

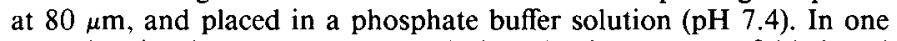
case, the visual cortex was removed, the calcarine cortex unfolded, and all of area 17 flattened between glass slides. The flattened cortex was then cut parallel to the pial surface. Sections were reacted with diaminobenzidine using either cobalt chloride or nickel-enhanced cobalt chloride to intensify the reaction (Adams, 1977, 1981), mounted on chrome alum subbed slides, defatted, cleared in xylene, and coverslipped unstained. Following analysis of HRP-filled afferents, representative sections were stained with cresyl violet.

Selection of HRP-filled axons. Injections of HRP resulted in a dark patch of label in the white matter from which densely filled fiber bundles emanated. These bundles could be followed for considerable distances; many could be traced back to the LGN. Within the cortex itself, individual bundles projecting to striate cortex would disperse near layer VI as axons left the white matter. Generally, each bundle of labeled axons terminated within a discrete region of striate cortex; many filled processes terminated within layer IV and layer VI, causing them to stand out against the lighter background of the other layers. Filled fibers could also be traced to terminal points in layer III and occasionally in layer II.

We restricted our analysis to axons that could be traced several millimeters within the white matter, with branches that had well-filled boutons and that could be followed to terminal points. Axons terminating in layers other than layer IV were excluded from our analysis since some of these layers receive projections from numerous non-LGN sources. Although layer IV of striate cortex receives other inputs (see Discussion), we did not see filled axons with distributions in layer IV that might suggest they originated from non-LGN sources (i.e., fine fibers that terminated throughout layer IV and/or in additional layers). Perhaps, the technique is selective for larger fibers or perhaps we selected against non-LGN fibers because they were less well filled. Regardless, the wellfilled axons that were selected for analysis all terminated primarily within either the upper or lower half of layer IV, suggesting that they originated in the LGN (see Discussion for fuller treatment of this point).

Reconstruction of HRP-flled axons. HRP-filled fibers that ramified in layer IV of striate cortex were serially reconstructed at a total magnification of $630 \times$ using a Leitz $63 \times$ oil-immersion plan apochromatic objective on a Zeiss microscope equipped with a drawing tube. As discussed above, axons were chosen for reconstruction if the HRP filling was complete from the axon trunk to the terminal "swellings" or boutons. Selected regions of the axon trunks and terminal arbors, drawn at a total magnification of $1000 \times$ using a Nikon $100 \times$ oil-immersion plan apochromatic objective, were used for measurements of axon and bouton size and bouton number. Contirmation of the laminar borders within which each afferent ramified was obtained after counterstaining. All axon trunks were followed well into the white matter to ensure that they were fully reconstructed and were from cells extrinsic to area 17.

Data analysis. To calculate the extent of the terminal arbor parallel to the cortical surface, measurements were made of the distance between the tips of the most widely spread branches in the anteroposterior (AP) and in the mediolateral (M-L) dimensions. These measures were multiplied to get an estimate of the area of cortex covered by each arbor in layer IV.

Most of the arbors from which quantitative analyses were made were reconstructed from cortices sectioned in the parasagittal plane. To estimate the shape of the arbors in a plane parallel to the pial surface, dorsal view reconstructions were made by plotting the arrangement of boutons as if viewed from the pial surface. For this analysis, 2 methods were used initially. Using the first method, the organization of boutons, as plotted on the original reconstructions, was translated onto a second piece of paper and aligned such that all boutons from one section were arranged (maintaining nearest-neighbor relationships) within a space equal to the width of that section. Boutons from consecutive sections were then oriented so that the overall shape of the arbor could be accurately reflected.

Using the second method, successive sections were reconstructed at a total magnification of $630 \times$, moving through and across sections from medial to lateral. Near-neighbor relationships were judged by plotting all the boutons in one plane of focus. The focus was then moved in increments of one-tenth the thickness of the section, and all boutons found in this plane of focus were plotted adjacent to the others. This procedure was continued until the entire thickness of the section had been analyzed; then the procedure was repeated for the adjacent section, and so on. When moving from section to section, correct alignment within the arbor was maintained. The first method proved to be the simplest and gave results that were virtually identical to the second method, which involved a more lengthy process. Therefore, most of the arbors were reconstructed to a dorsal view using the simpler approach.

In order to quantify the elongation of terminal arbors in a plane parallel to the pial surface, a symmetry index was calculated. This index was the ratio of the larger diameter of the arbor to the smaller diameter. The symmetry index does not reflect whether the A-P dimension or the $M-L$ dimension was the longer; instead, it indicates the relative degree of elongation within area 17.

To assess axon diameter, the axon trunk proximal to the first known branch point was viewed under a $100 \times$ objective at a total magnification 


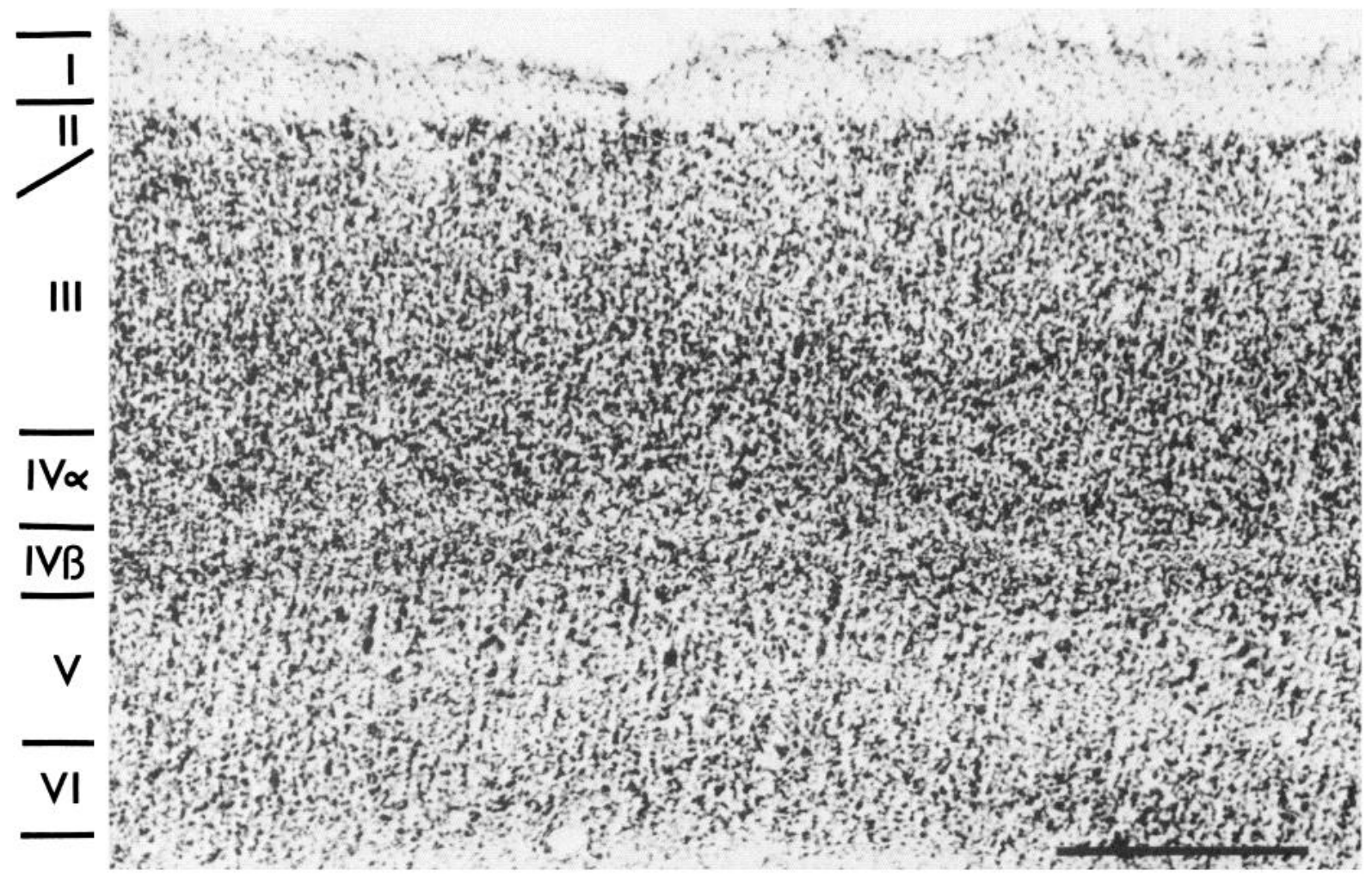

Figure 1. Light-field photomicrograph of a Nissl-stained section through striate cortex of an adult galago (Galago senegalensis senegalensis). Our own investigations into cortical lamination in primates have led us to adopt the scheme of Hässler (1967). For comparison with Hässler's scheme, Brodmann's scheme is indicated in parentheses: I (I); II (II); IIIA (III); IIIB (IVA); IIIC (IVB); IV $\alpha$ (IVC $\alpha$ ); IV $\beta$ (IVC $\beta$ ); V (V); VI (VI). In galagos there is no layer IVA as defined by Brodmann. Scale bar, $100 \mu \mathrm{m}$.

of $1000 \times$. The axon was traced using the drawing tube attachment at 5 different points along its length near the bifurcation, where labeling appeared to be complete throughout the width of the axon. The width of the axon at each point was determined, and the mean axon diameter was then calculated.

To determine the size and number of boutons, an area of dense arborization from each of the best-filled axons was traced at $1000 \times$ total magnification using a drawing tube attachment. From these tracings, the size of boutons was assessed for each axon by measuring bouton area for a sample of approximately 100 boutons. The means of the bouton areas were obtained for each arbor for statistical comparison. To determine the number of boutons within a restricted length of axon, the high-magnification tracing of the area of densest arborization was used again. For each axon, the number of boutons along a $50 \mu \mathrm{m}$ length of axon was counted for a randomly chosen branch of axon in the tracing. The counts were then repeated on a total of 4 branches from the tracing. From these 4 counts, the mean number of boutons within a $50 \mu \mathrm{m}$ length of axon arbor was determined for each axon.

Quantitative measures of the morphological parameters of arbors and parent axons were determined with the aid of a Bioquant Image Analysis System ( $R$ and M Biometrics). Statistical significance was determined by a 2 -tailed $t$ test for independent samples. In addition, we determined the strength of these effects by determining the percentage of the overall variance accounted for by each $t$ test by calculating an omega-squared value (Hayes, 1973). In some instances, quantitative measures were at or near the limit of resolution of the light microscope $(0.3-0.5 \mu \mathrm{m})$, and thus any statistical differences can only be interpreted as suggestive of real differences; these would require quantification at the electron microscopic level to determine if significant differences actually existed (Friedlander et al., 1981).

\section{Results}

A total of 55 HRP-filled axons that ramified in layer IV of striate cortex were reconstructed for this study; all were followed to the white matter, allowing them to be positively identified as afferent axons originating from cells at some distance from the site of termination. Analyses were performed on well-filled axons collected from lesser galagos, some of which were reconstructed from area 17 after the cortex had been flattened and sectioned parallel to the pial surface. Additionally, 10 axons reconstructed from layer IV in striate cortex of greater galagos were analyzed for species comparison.

\section{Cytoarchitecture of striate cortex in galagos}

Striate cortex (area 17) in galagos, as in all mammals, receives a retinotopic representation of the contralateral visual hemifield primarily from the LGN. Within this area (which is situated at the caudal pole of the cerebral hemisphere), central vision is represented on the dorsolateral surface (the dorsal bank) of the occipital lobe and peripheral vision is represented in the calcarine fissure (Weller and Kaas, 1982).

Striate cortex is clearly laminated in galagos, as in other primates, and the characteristics of each layer have been described in detail by numerous investigators (Brodmann, 1909; Hässler, 1967; Diamond et al., 1985). To identify the layers and sublayers of galago striate cortex we used the nomenclature described by Hässler (1967). Based on this system, 6 layers can be distinguished in Nissl-stained sections (Fig. 1). Layer I lies nearest the pial surface and contains few cell bodies. Layer II is a thin band of densely packed cells, lying directly adjacent to layer I. Layer III is a fairly broad layer containing mainly small pyramidal cells and a few stellate cells. The border between lower layer III and upper IV $\alpha$ is sometimes difficult to distinguish, although in general, layer IV $\alpha$ is more cell dense than III and contains 
primarily stellate cells. The border between IV $\alpha$ and IV $\beta$ can be readily identified because layer IV $\beta$ generally contains more densely packed cells than IV $\alpha$. Layer $\mathrm{V}$ can be distinguished from layer IV by its large, scattered pyramidal cells; it is also easily distinguished from layer VI, which contains numerous darkly stained cells.

Hässler's system of naming cortical layers differs from that used by Brodmann (1909), the latter being commonly applied in descriptions of macaque monkey striate cortex. For convenience of comparison, however, we have also indicated in the figure legend, in parentheses, the laminar designations of Brodmann. The major discrepancy concerning layer identity involves layers III and IV. In galagos, there is no discernible IVA in Brodmann's terminology and no thalamic input to the equivalent of this zone (Diamond et al., 1985); however, there is patchy input from the small-celled (koniocellular) LGN layers to the equivalent of Brodmann's layer III (Casagrande and DeBruyn, 1982; Diamond et al., 1985). As in monkeys, the magnocellular and parvocellular LGN layers in galagos project to layers IVC $\alpha$ and IVC $\beta$, respectively, in Brodmann's terminology.

\section{Qualitative features of afferent axons}

In galagos, axons terminating in layer IV of striate cortex form 2 distinct, morphological types; for convenience these are termed type I and type II axons. A qualitative morphological description of type I and II axons precedes discussion of the results from quantitative analyses. Because type I axons are large and terminate in the upper tier of layer IV, they are presumed to originate from neurons in the magnocellular LGN layers. Likewise, because type II axons are small in caliber and terminate in the lower tier of layer IV, they are presumed to originate from parvocellular LGN cells. Since we found no evidence for axons bifurcating deep in the white matter, as has been described in cats (Humphrey et al., 1985), we have illustrated only a small portion of the parent axon within the white matter.

All type I afferent axons have large terminal arbors and largecaliber axons. As can be seen in the examples shown in Figures 2 and 4, despite the considerable variability in the branching patterns of type I axons, all type I afferents share in common a main projection to the upper tier of layer IV $(\mathrm{IV} \alpha)$. Additionally, they often have branches within upper IV $\beta$ and lower III (see also Figs. 3 and 5). A small proportion ( 2 of 38 ) of the type I axons in this sample bifurcate near layer VI and arborize in 2 discrete loci in layer IV (see Fig. 2a). This sample is unusual in that each terminal patch is confined to a very small area (see below). Thus, these 2 axons may represent a separate axon subclass that was only rarely encountered in our material.

Type II axons ramify primarily in layer IV $\beta$ and have restricted tcrminal arbors and small-caliber axon trunks (see Figs. 6 and 7). Type II afferents seldom terminate in layer V; however, they span a short distance into layer IV $\alpha$ (see Fig. 8). Figure $7 d$ illustrates a type II axon whose axon trunk courses a long distance though layer IV before arborizing in one primary locus in IV $\beta$. The more typical pattern, however, is for the axon to branch profusely immediately upon entering the target layer.

Both types of axons have collateral arborizations in layer VI; however, this bilaminar arborization pattern is more frequent for type I than type II axons. Additionally, the density of branches in layer VI is much greater for type I axons than for type II axons (for example, compare Figs. 2-5 with Fig. 7f). Type I axons occasionally ramify across the entire thickness of layer
VI (Fig. 3); however, they more frequently have restricted projections to the lower half of layer VI (see Fig. 5). The type II fibers have such sparse projections to layer VI that it is impossible to determine whether they ramify primarily in a subtier of that layer. It is possible that, because of their small size, the finest branches tend to be less well filled. However, incomplete filling would not account for the lack of major collateral branches from type II axons in layer VI.

The terminal arbors of both type I and type II axons are studded with terminal boutons or "swellings" (see Figs. 3, 5, and 8). As shown in Figure 9, boutons on both afferent types are organized in serial chains and rarely occur in the clusters that are commonly seen on retinogeniculate axons (Mason and Robson, 1979; Bowling and Michael, 1980, 1984; Sur and Sherman, 1982; Sur et al., 1987). Notice also that the boutons are smooth and round in shape, and are separated by short lengths of very fine caliber axon.

\section{Quantitative features of axons}

Results from quantitative analyses of axon diameter and terminal arbor size from lesser galagos are shown in Figures 10 and 11 . In these figures, axons reconstructed from the dorsal bank are highlighted by hatching to illustrate that there are quantitative differences within a sample based on visual field position of the axon. For initial comparison of type I and type II afferents, data were pooled for all visual field eccentricities. As can be seen in Figure 10, there is some overlap in the ranges of type I and type II axon sizes; however, the mean diameter ( \pm SEM) of type $I$ axons $(2.9+0.1 \mu \mathrm{m})$ is significantly larger than that of type II axons $(1.5 \pm 0.2 \mu \mathrm{m}, t=3.7 ; d f=27 ; p<$ 0.001 ), and this mean difference accounted for $30.4 \%$ of the overall variance. Similarly, although there is some overlap in size of terminal arbors for these 2 samples (Fig. 11), the mean size of type $I$ arbors $\left(0.08 \pm 0.01 \mathrm{~mm}^{2}\right)$ is significantly larger than the mean size of type II arbors $\left(0.03 \pm 0.01 \mathrm{~mm}^{2}\right)(t=$ $2.8 ; d f=27 ; p<0.01)$. This accounted for $19.1 \%$ of the overall variance between these samples.

The individual terminal arbors of the 2 rather unusual axons that bifurcate and arborize in 2 discrete loci of layer IV $\alpha$ are surprisingly small, averaging $0.009 \pm 0.003 \mathrm{~mm}^{2}$. This is only one-tenth the size of the type I arbors that ramify in only one locus. It is likely that these bifurcating axons represent another class of axon that is not well represented in our samplc.

Measurements of bouton area indicate that there is no statistical difference between the size of boutons on type I and type II axons. However, counts of boutons demonstrate that along a single $50 \mu \mathrm{m}$ length of of axon arbor, type II axons have significantly more boutons than type I axons, averaging $13.5 \pm$ 0.76 and $11 \pm 0.42$ boutons, respectively $(t=3.06 ; d f=13$; $p<0.001$ ) (Fig. 12). The latter mean difference accounts for $59.7 \%$ of the overall variance between these samples.

Dorsal reconstructions of the arrangement of boutons on terminal arbors, shown in Figure 13, yielded 2 findings. The first is that boutons appear to be randomly spaced throughout the area of arborization, with the exception of the axon illustrated in Figure 13c. The organization of boutons in this axon is similar to that shown by Blasdel and Lund (1983) with boutons clustered like walls around empty lacunae. The second result is that the terminal arbors themselves are often elongated, rather than being circularly symmetric. In Figure 13, the dashed line around the outermost boutons emphasizes this point.

To ensure that the shape of the terminal arbors, as determined 

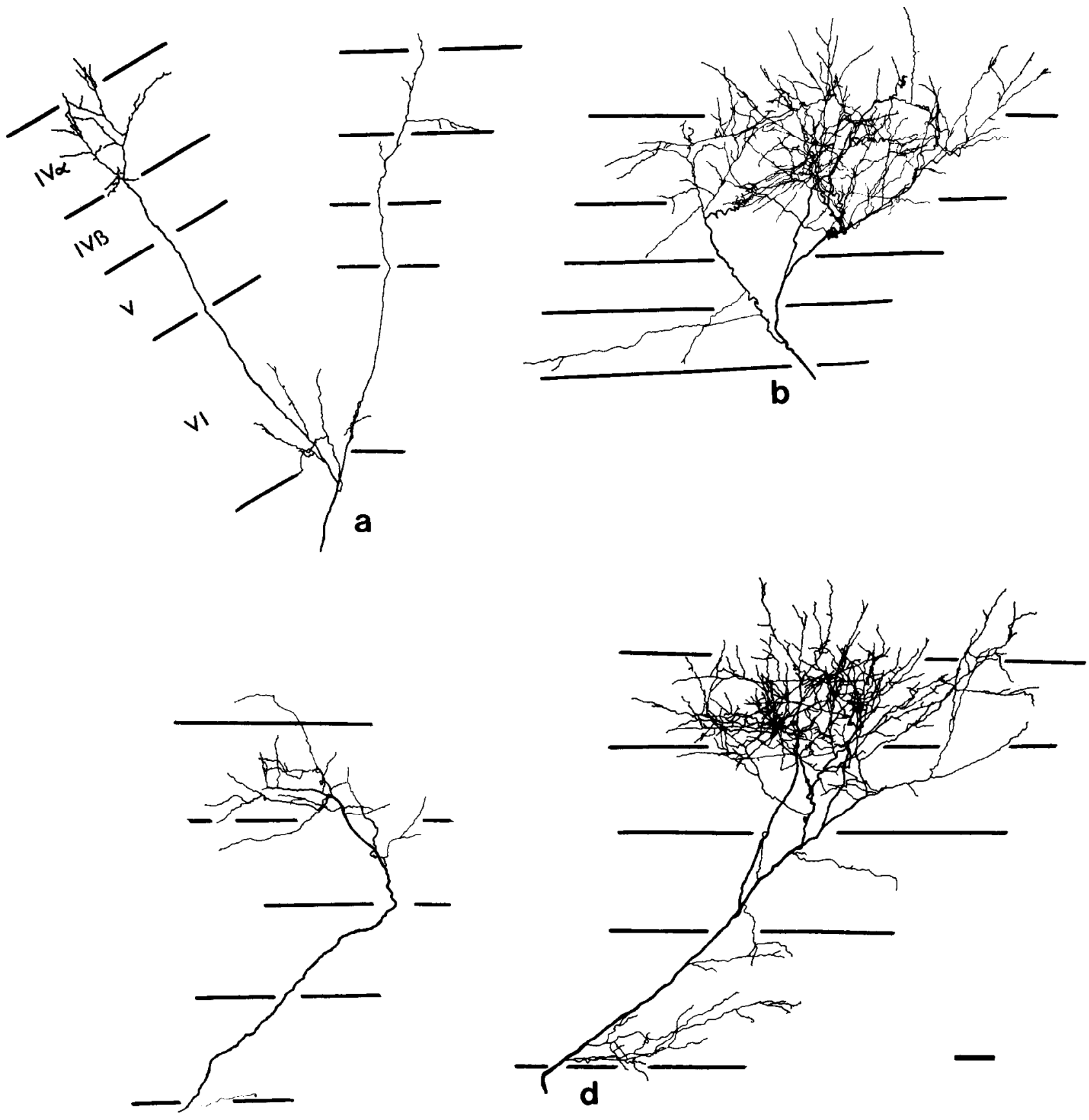

C

Figure 2. Composite of type I axons serially reconstructed from the dorsal bank of striate cortex showing the extent of their variation in lesser galagos. Solid lines indicate borders of cortical layers; roman numerals identify layers according to Hässler's nomenclature. Note that all axons arborize primarily in layer IV $\alpha$ but also project to layer III and to layer VI. In some cases, the course of the axon after reaching the white matter has not been illustrated to conserve space. The magnification in this figure is the same as in Figures 4,6 , and 7 to allow for direct comparisons. Scale bar, $50 \mu \mathrm{m}$.

from the dorsal reconstructions, is an accurate reflection of axon morphology, 7 axons terminating in layer IV were reconstructed from striate cortex that had been flattened following injections of HRP into the white matter. Because of the difficulty in defining divisions between IV $\alpha$ and IV $\beta$ in flattened hemispheres, these 7 axons were not distinguished by type; however, the major conclusion from this analysis would not be altered by identification of axon types. As shown in Figure 14, most of the arbors from the flattened cortex are elongated. The arbors are not con- sistently elongated in either the A-P or M-L dimension, but instead are often elongated at some angle oblique to both A-P and M-L. The arbor illustrated in Figure $15 d$ measures $750 \times$ $1000 \mu \mathrm{m}$ and has the largest terminal field reconstructed in this study. This afferent is located on the dorsal bank of striate cortex and is clearly elongated in the M-L dimension.

A symmetry index was used to make an objective comparison of the elongation of arbors between the sample of axons reconstructed from the flattened hemisphere and the axons recon- 


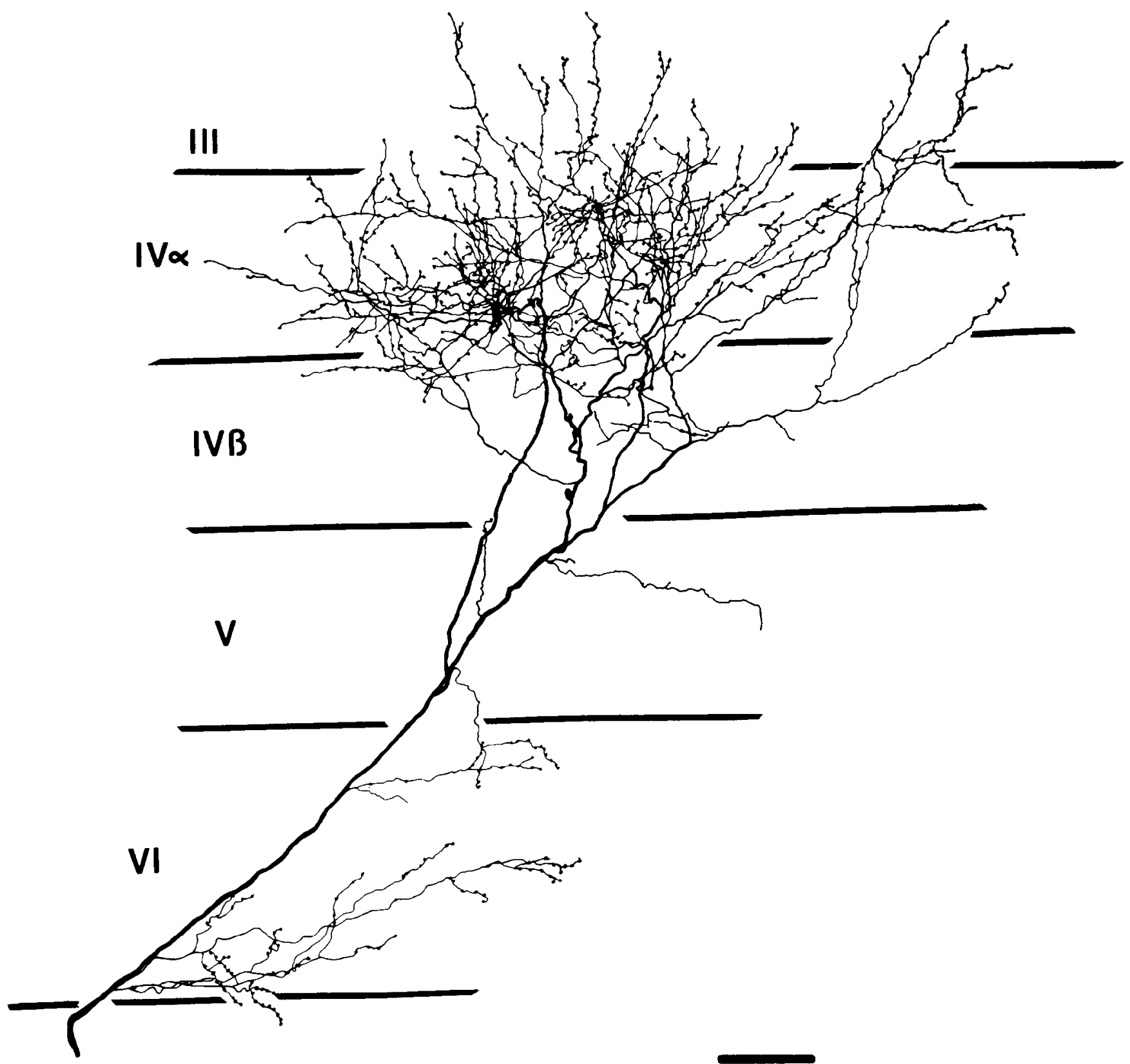

Figure 3. Serial reconstruction of a type I axon from the dorsal bank of striate cortex of a lesser galago. This axon (also shown at lower power in Fig. $2 d$ ) projects primarily to IV $\alpha$, but some branches extend approximately $75 \mu \mathrm{m}$ into lower layer III. Additionally, the axon projects to layer VI, where branches are concentrated in the lower half of the layer. The size of the boutons has been enhanced to demonstrate their distribution on the terminal arbor branches. Note that the terminal branches are studded with boutons. Conventions as in Figure 2.

structed from the parasagittally sectioned cases. The symmetry index for a perfectly symmetric arbor would be 1.0 , and since this index is calculated by dividing the larger arbor diameter by the smaller, all indices will be greater than or equal to 1.0. This analysis demonstrates that, regardless of the plane of section, arbors are elongated (see Fig. 15). The average arbor is 1.5 times greater in length than in width for both samples regardless of fiber type.

\section{Central-peripheral differences}

Arbors in area 17 were reconstructed from both the dorsal bank, containing the representation of the central visual field (Figs. 2, 3,6 , and 8 ), and the calcarine fissure, containing the peripheral visual field representation (Figs. 4, 5, and 7). These 2 samples were compared to determine whether the morphology of individual geniculostriate arbors changes in relation to topography. Significant differences were found. Measurements of parent axon diameters indicate that axons on the dorsal bank are significantly larger than those in the calcarine fissure, measuring $3.7 \pm 0.18$ and $2.5 \pm 0.24 \mu \mathrm{m}(t=2.5 ; d f=17 ; p<0.05)$, respectively, for type $\mathrm{I}$ axons and $1.9 \pm 0.26$ and $1.4 \pm 0.14 \mu \mathrm{m}(t=2.11$; $d f=10 ; p<0.05$ ), respectively, for type II axons (see Fig. 10). These differences are very reliable since they account for 22.6 and $22.3 \%$ of the overall variances, respectively. Additionally, terminal arbors occupy more territory parallel to the cortical layers on the dorsal bank than in the calcarine sulcus (see Fig. 

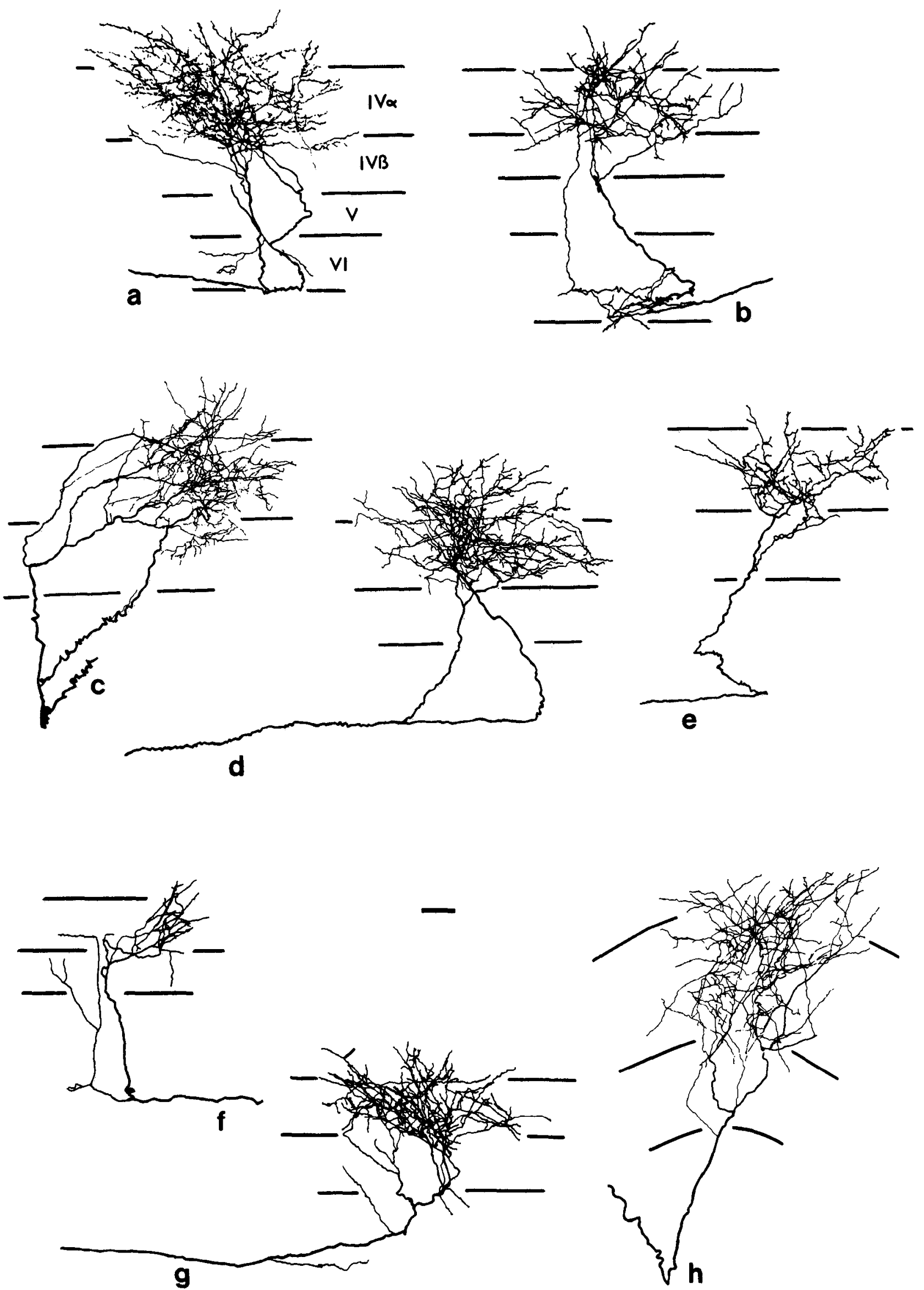

Figure 4. Composite of type I axons serially reconstructed from the calcarine fissure of striate cortex showing the extent of their variation in lesser galagos. Cortical layers IV $\alpha$-VI are illustrated in $a$ and $b$; however, only layers IV $\alpha$ and IV $\beta$ are shown in $c-h$. The axons project primarily to layer IV $\alpha$ with a minor projection to lower layer III and occasional branches in layer VI. In $c$ and $h$, the axon trunk distal to the terminal arbor appears to be coursing toward layer IV; however, this merely reflects the curvature of the cortex. Conventions as in Figure 2. 


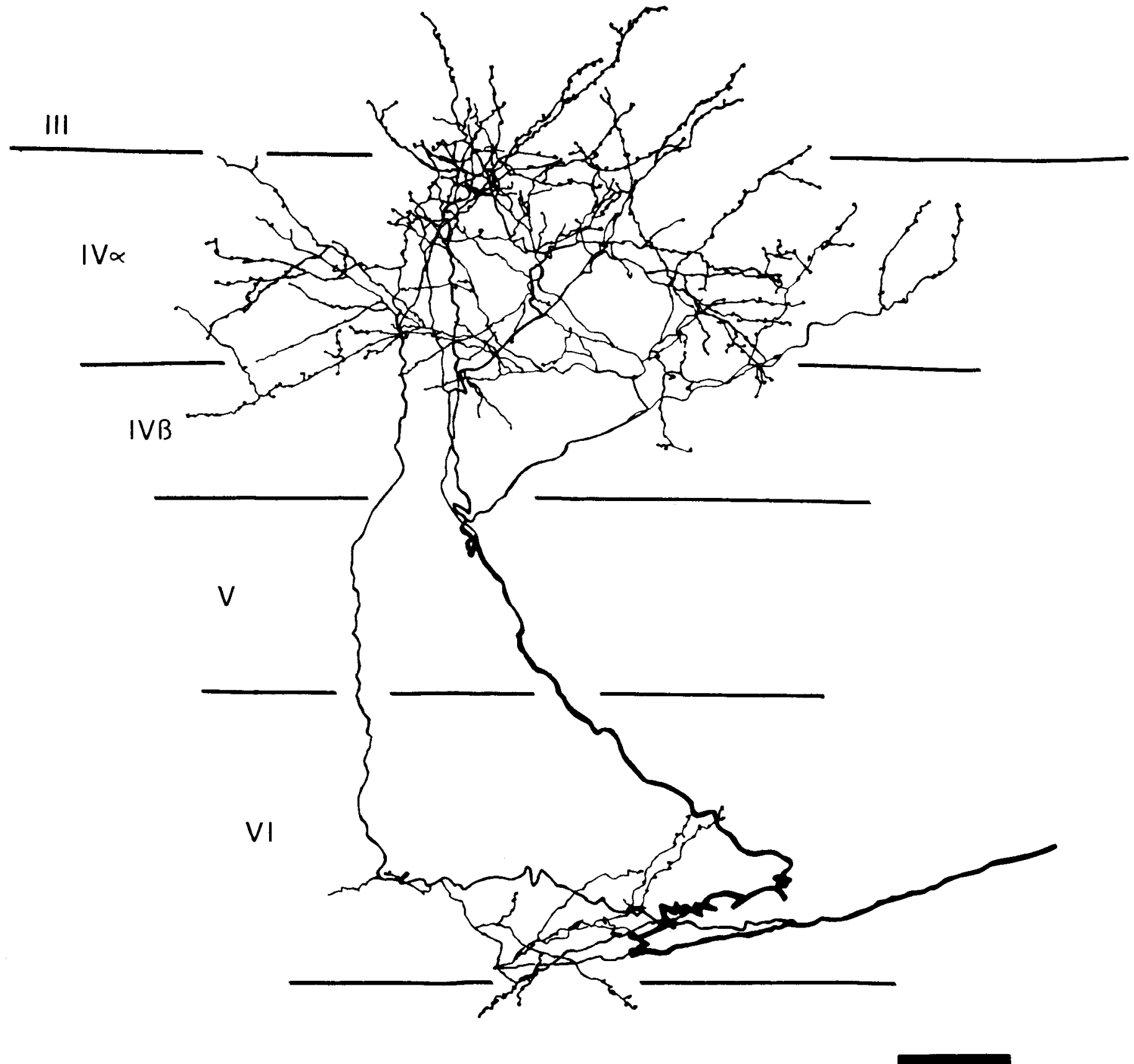

Figure 5. Serial reconstruction of a type I axon from the calcarine fissure of a lesser galago. This axon is also shown at lower magnification in Figure $4 b$. In addition to the primary projection to layer IV $\alpha$, this axon ramifies approximately $50 \mu \mathrm{m}$ into lower layer III and also in the lower half of VI. The size of the boutons has been enhanced to demonstrate their distribution. Conventions as in Figure 2.

11). The mean size of type I arbors on the dorsal bank is significantly larger than in the calcarine fissure, measuring $0.14 \pm$ 0.04 and $0.054 \pm 0.007 \mathrm{~mm}^{2}$, respectively $(t=2.77 ; d f=12$; $p<0.05$; compare Figs. 2 and 4). Additionally, the mean size of type II arbors on the dorsal bank is significantly larger than in the calcarine fissure, measuring $0.049 \pm 0.008$ and $0.023 \pm$ $0.003 \mathrm{~mm}^{2}$, respectively $(t=2.78 ; d f=6 ; p<0.05$; compare Figs. 6 and 7). Again, calculations of the omega-squared values demonstrate that the latter differences are reliable since 32.3 and $45.5 \%$, respectively, of the overall variance is accounted for in each case.

\section{Species differences}

Ten axons were serially reconstructed from greater galagos; 8 of these were classified as type I axons and 2 were identified as type II axons. Of the 8 type I axons, 3 bifurcate, ramifying in 2 discrete terminal loci. In these cases, it is not uncommon for one of the 2 loci to be larger than the other, as if one is a major site of innervation and the other secondary (see Fig. 16). The mean size of terminal arbors of bifurcating axons is only approximately half as large as the mean size of arbors on axons that do not bifurcate $\left(0.053 \pm 0.014\right.$ and $0.134 \pm 0.045 \mathrm{~mm}^{2}$, 

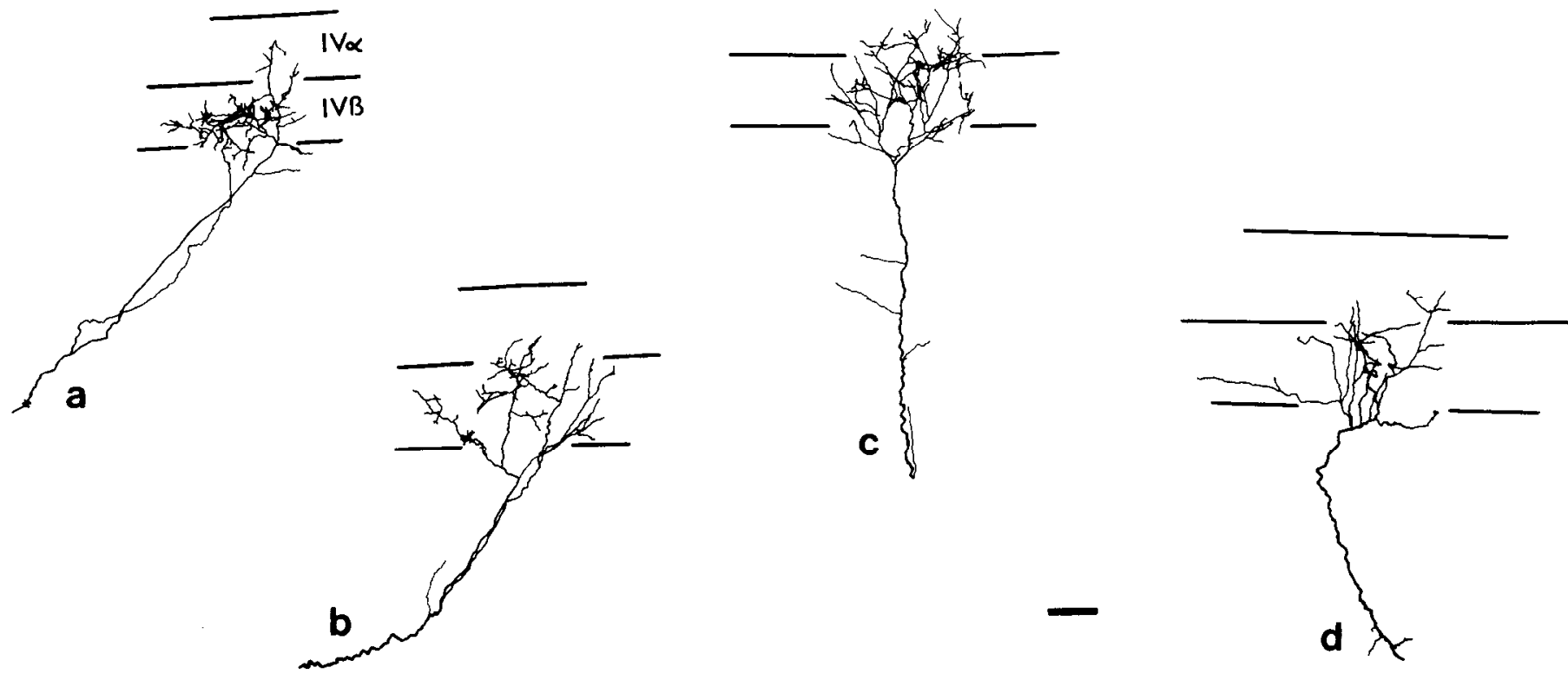

Figure 6. Composite of type II axons serially reconstructed from the dorsal bank of striate cortex in lesser galagos showing the differences in their morphology. These axons ramify primarily in layer IV $\beta$. Note that these'type II axons are markedly smaller than the type I axons from the same cortical region (see Figure 2). Conventions as in Figure 2. (Note: This figure is slightly reduced in comparison to Figures 2,4 , and 7. )

respectively). However, with the small sample size and the large variability, this difference is not statistically significant. The distance separating the 2 arbors of bifurcating axons varies from 240 to $850 \mu \mathrm{m}$. It should be stressed that the bifurcating axons seen in greater galagos are very similar to bifurcating axons seen in cats and monkeys (Blasdel and Lund, 1983; Humphrey et al., 1985) and likely comprise a morphological subtype of type I axons in galagos. These bifurcating axons can be contrasted with the 2 bifurcating axons scen in lesser galagos, which, because of their small size, may represent a separate type.

Comparison of arbor sizes between the greater and lesser galagos indicates that the average size of type I arbors that do not bifurcate are not significantly different between the species, although mean sizes are somewhat larger in greater than in lesser galagos. There were not enough type II arbors reconstructed from area 17 in greater galagos to allow comparison with thuse from lesser galagos.

\section{Discussion}

The present work represents the first study in which a large enough sample of geniculocortical axons was reconstructed to allow statistically meaningful comparisons to be made between axon types at different visual field eccentricities in striate cortex. The terminal arbors of individual axons innervating layer IV of striate cortex in galagos form 2 groups, based upon differences in sublaminar distribution and morphology. Evidence from present and past work suggests that these 2 groups of axons, which we have designated type I and II axons, represent the axonal endings of physiologically distinct $Y$-like and $X$-like cells, respectively, from the magnocellular and parvocellular layers of the LGN (Glendenning et al., 1976; Casagrande and DeBruyn, 1982; Norton and Casagrandc, 1982; Conley et al., 1985; Diamond et al., 1985; Irvin et al., 1986; Norton et al., 1988). Our results show that type I (presumed Y-like) axons occupy relatively more cortical space within their main terminal sublayer
(IV $\alpha$ ), possess fewer numbers of boutons along a restricted length of axon, and arborize more frequently in cortical layer VI than is the case for the type II (presumed X-like) arbors, which ramify in layer IV $\beta$. Additionally, for both types of fibers, arbor size is not constant across the representation of visual space in cortex, and fibers tend to be elongated in shape.

In the discussion that follows we consider first the implications of these observations for the transfer of visual information from the LGN to visual cortex in galagos. We then compare our observations with those of others, principally from work done in cats and macaque monkeys, in an effort to establish general relationships between these morphological observations and visual system performance. Since no galago species differences were found in the structural characteristics of afferent axons (outside of the fact that the few axons that bifurcate in lesser galagos have very small terminal arbors and occur less frequently than in greater galagos), the discussion will focus on data obtained from lesser galagos.

\section{Evidence that axons originate in the $L G N$ and a comment on nomenclature}

Since the axons described in the present study were bulk-filled from the white matter of striate cortex, it is possible that they originate from sources other than the LGN. In macaque monkeys, more than 16 cortical and subcortical inputs to striate cortex have been described (Benevento et al., 1975; Ogren and Hendrickson, 1977; Spatz, 1977; Tigges et al., 1977, 1982; Rezak and Benevento, 1979; Rockland and Pandya, 1979; Doty, 1983). Even though not all of these sources have been identified in galagos, similarities between monkeys and galagos in the projection patterns that have been identified (Carey et al., 1979; Weller and Kaas, 1982) suggest that inputs to striate cortex in galagos likely resemble those seen in monkeys.

Regardless, we are confident that the axons we describe originate, not simply from the LGN, but also from specific LGN 

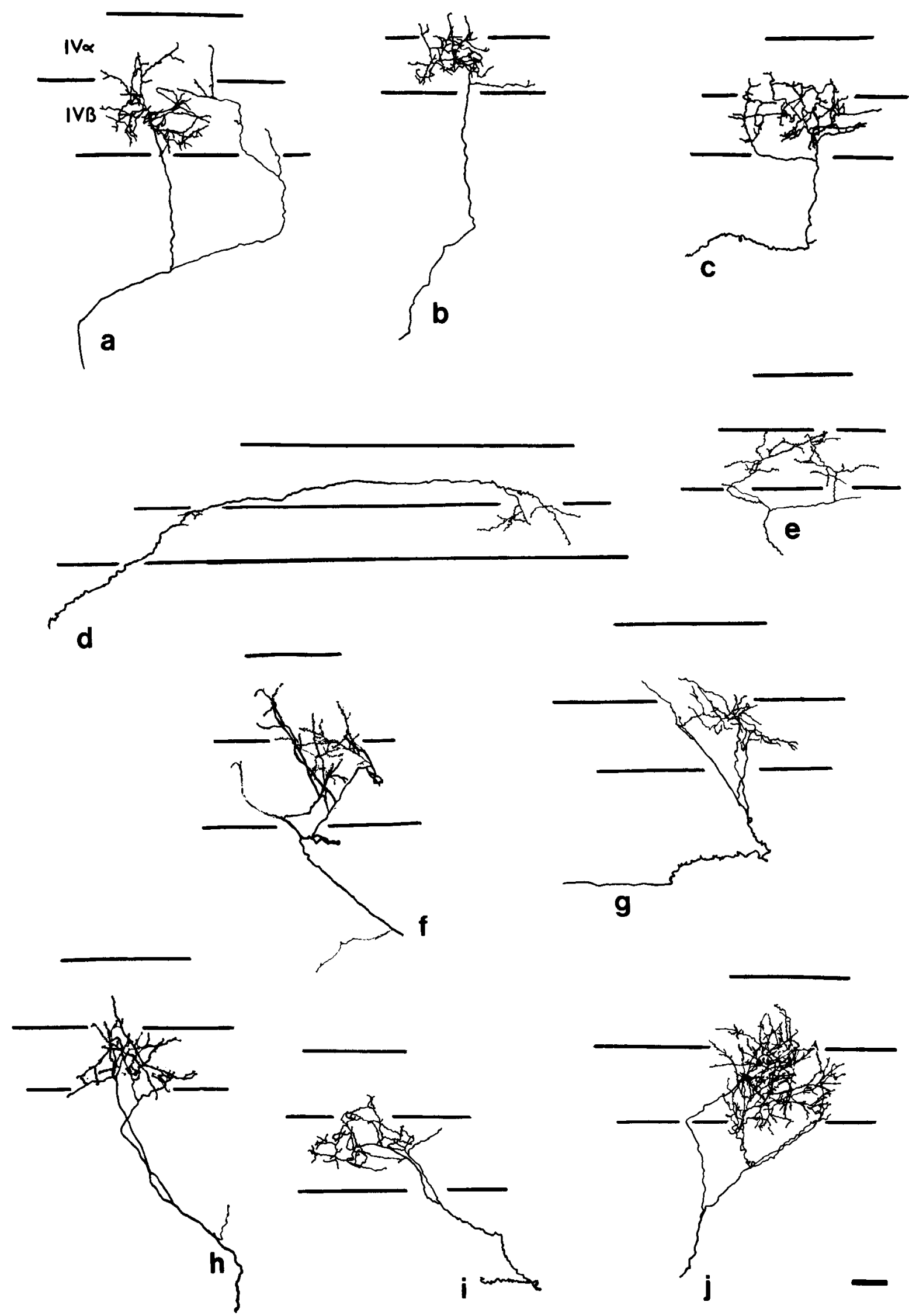

Figure 7. Composite of type II axons serially reconstructed from the calcarine fissure of striate cortex in lesser galagos showing the differences in their morphology. These axons ramify primarily in layer IV $\beta$ and seldom project to layer VI (see $f$ and $h$ for exceptions). The axon designated $d$ is unusual in that the axon trunk runs parallel to the cortical layers for a considerable distance before branching at the terminal locus. Comparison of the terminal arbor size of these axons with type I axons from the same cortical area (see Fig. 4) demonstrates a significant difference. Conventions as in Figure 2. 

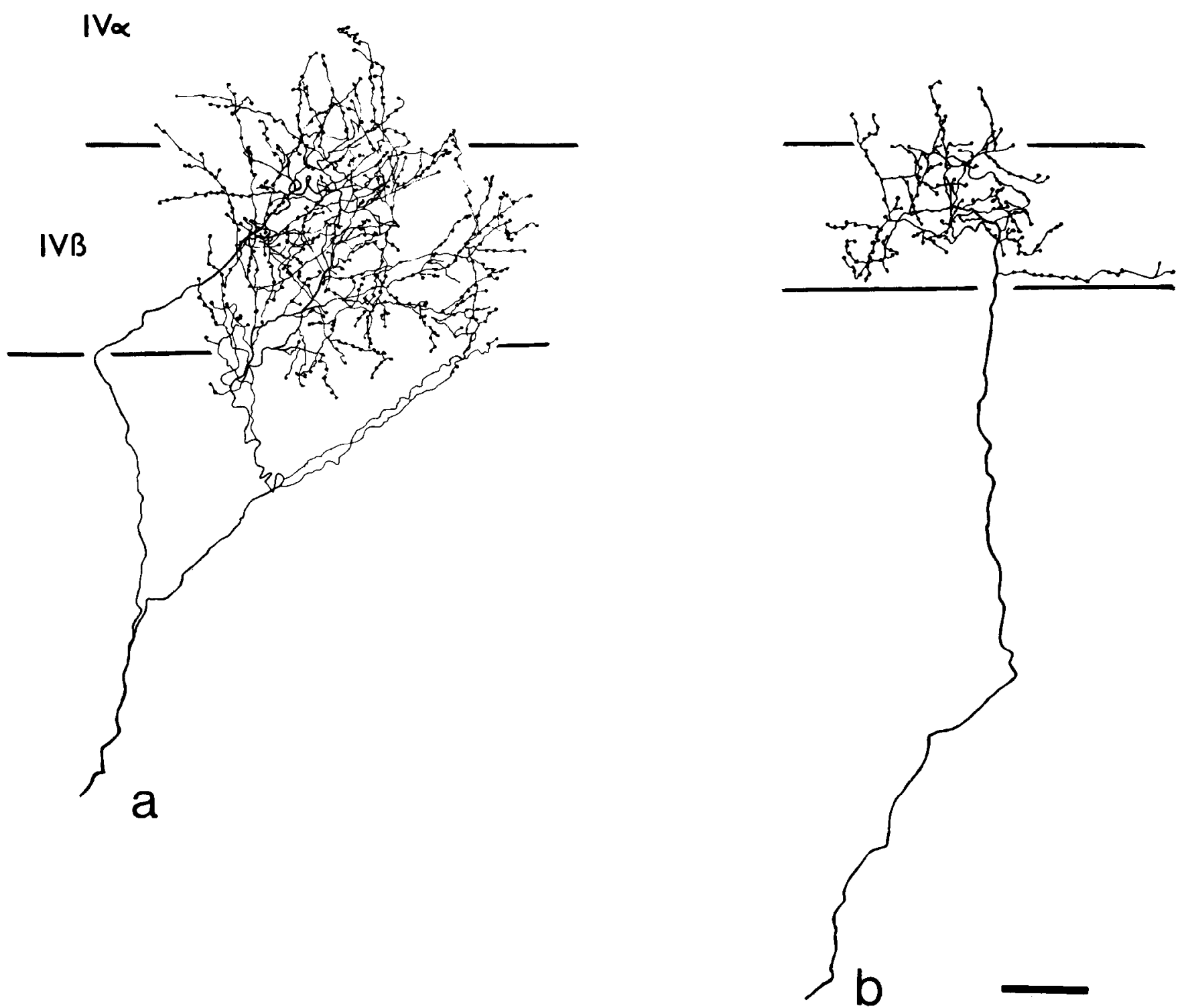

Figure 8. Serial reconstruction of 2 type II axons from the dorsal bank of striate cortex in lesser galagos showing details of arbor and bouton distribution typical for this axon type. Both axons project primarily to IV $\beta$; however, the axon designated $a$ ramifies across half of layer IV $\alpha$ as well as into layer V. The axon designated $b$ is restricted primarily to IV $\beta$, with only a few branches crossing the IV $\alpha-I V \beta$ border. Neither axon projects to layer VI. Conventions as in Figure 2.

layers, namely, the magnocellular and parvocellular layers. There are 2 main reasons for this interpretation. First, examination of the distribution of degencrating profiles or transported label from individual LGN magnocellular and parvocellular layers in galagos has shown that these markers are restricted to the main cortical zones of termination of the type I and type II fibers, namely, layers IV $\alpha$ and IV $\beta$ (Glendenning et al., 1976; Casagrande and Skeen, 1980; Casagrande and DeBruyn, 1982; Diamond et al., 1985). A similar restriction of inputs into sublayers of layer IV of striate cortex from magnocellular and parvocellular LGN layers has been demonstrated in both New and Old World simian primates and thus likely represents a feature common to all primates (Hubel and Wiesel, 1972; Hendrickson et al., 1978; Blasdel and Lund, 1983; Fitzpatrick et al., 1983; Weber et al., 1983; see also Materials and Methods for further discussion of this point). Additionally, the known patterns of termination of nongeniculate sources to the striate cortex do not exhibit the sublaminar specificity possessed by the LGN projections. For example, the nongeniculate inputs that have terminations in layer IV either terminate diffusely throughout all cortical layers (e.g., the locus coeruleus projection) or are not restricted to subdivisions of layer IV (e.g., the claustral projection) (Carey et al., 1979; LeVay and Sherk, 1981; Tigges et al., 1982). Therefore, when individual axons are found to project specifically to one tier of cortical layer IV, it is most likely that those axons arise from the LGN. Second, the morphology of 

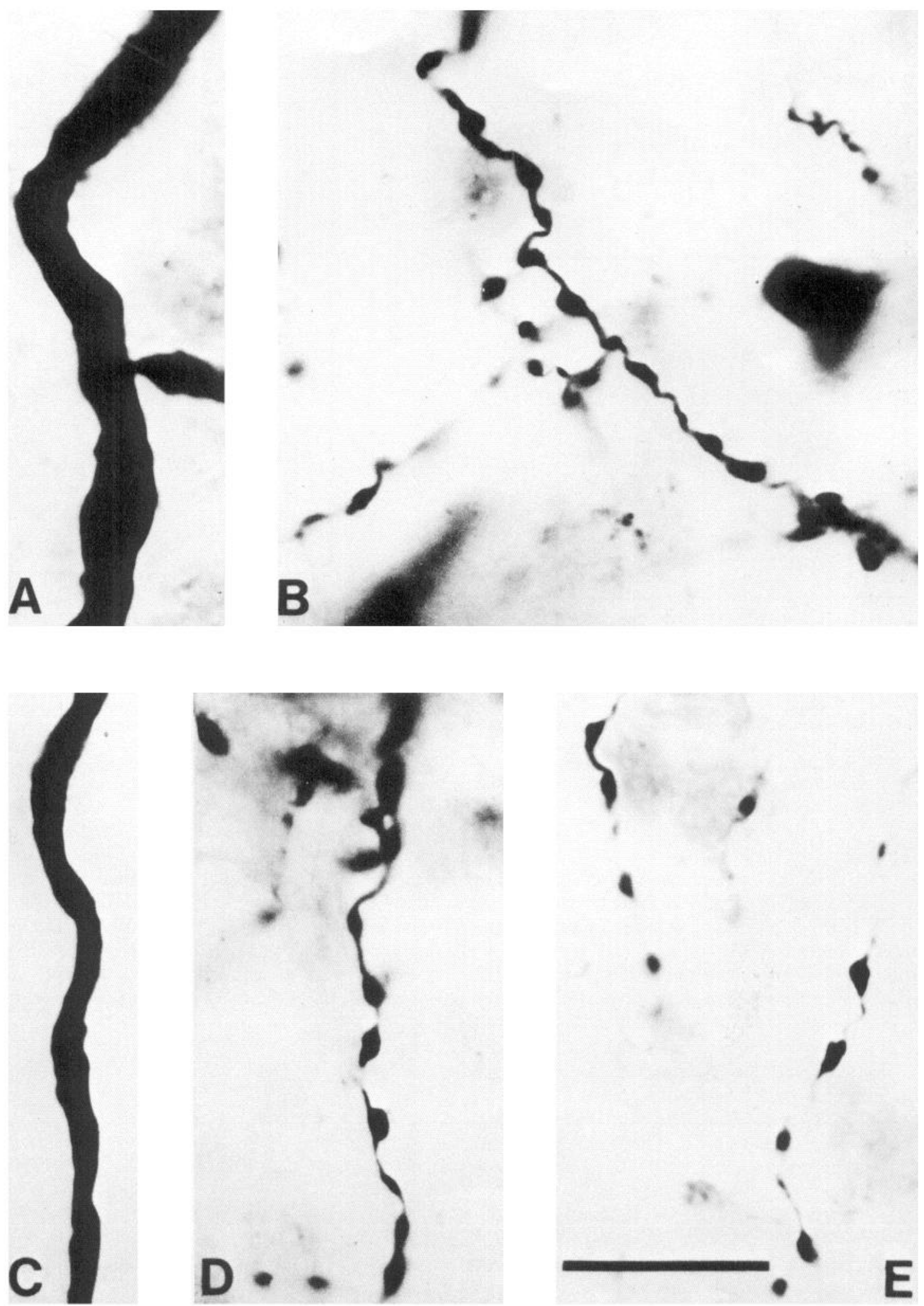

Figure 9. Photomicrographs showing the size and shape of boutons in comparison with the parent axon trunks for type I arbors $(A, B)$ and type II arbors $(C-E)$. Notice the fine caliber of the axon segments that separate individual boutons, in comparison with the axon trunks whose diameters measured $2.6 \mu \mathrm{m}$ for the type I axon $(A)$ and $1.5 \mu \mathrm{m}$ for the type II axon $(C)$. Also note that boutons on type I $(B)$ and type II $(D, E)$ arbors are very regular in shape. Scale bar, $10 \mu \mathrm{m}$. 


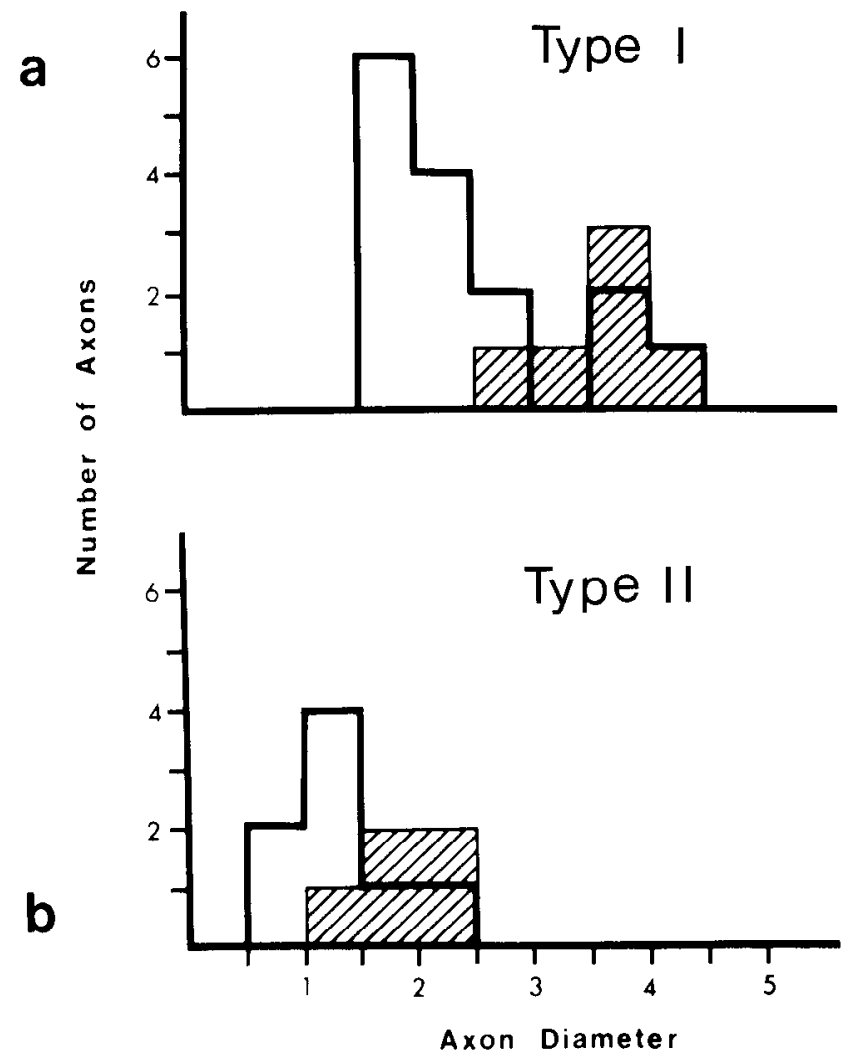

(u)

Figure 10. Bar graphs illustrating the diameter of parent axon trunks for type I afferents $(a)$ and type II afferents $(b)$. For both axon types, those sampled from the dorsal bank of striate cortex (hatched histogram), which represents central vision, have larger diameters on average than axons in the calcarine fissure (open histogram) which represents peripheral vision.

our type I and type II axons share many features in common with the morphology of physiologically identified magnocellular and parvocellular LGN axons ending in layer IV of macaque monkey (Blasdel and Lund, 1983).

The reason that we have designated our arbors type I and II also deserves brief comment. Although we speculate about the cell origin of these axons, we cannot trace them to their cell bodies. Therefore, it would be inappropriate to call them either magnocellular and parvocellular or X-and Y-like axons. We felt it most appropriate to use labels that were neutral, convenient, and did not suggest an origin or an essential feature (such as the designations large versus small). The terms type I and type II fulfill these requirements adequately without overlapping with terms used by others.

\section{Comparison of type I and type II axons}

There are 2 questions of interest concerning the fiber types we have described in cortex. How different are these axon types and, if they are different, what is the functional significance of this difference? Concerning the answer to the first, it is necessary to demonstrate that type I and II arbors truly represent 2 distinct populations, not extremes of a continuum. Of the relatively large sample $(n=55)$ of axon terminals reconstructed within layer IV, none span the full thickness of the layer; all show major terminal arbor concentrations either in the upper or lower portions of layer IV but never in the middle of the layer.

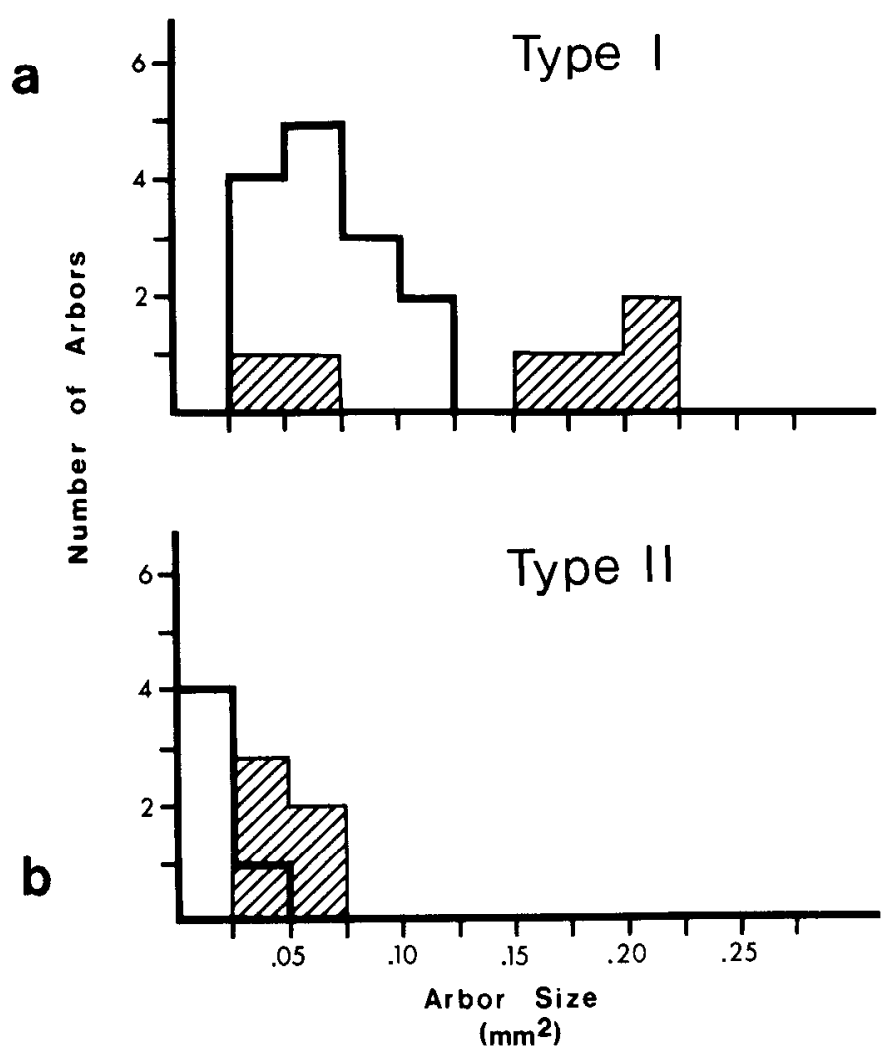

Figure 11. Bar graphs illustrating the cortical area occupied by type I $(a)$ and type II $(b)$ terminal arbors. In general, the arbors sampled from the dorsal bank of striate cortex (hatched histogram) spanned a larger cortical area than arbors in the calcarine fissure (open histogram). The 2 type I arbors reconstructed from the dorsal bank that measure less than $0.1 \mathrm{~mm}^{2}$ were less well filled, so their absolute arbor size is probably an underestimate.

The different target zones in layer IV for the 2 types of afferents indicate that type $I$ and II axons are communicating with separate populations of cortical neurons. At present, there are no data available concerning physiological or connectional differences between cortical cells that lie in either the upper or lower tier of layer IV of striatc cortex in galagos to validate this presumption. However, in macaque monkeys, recent evidence sug-

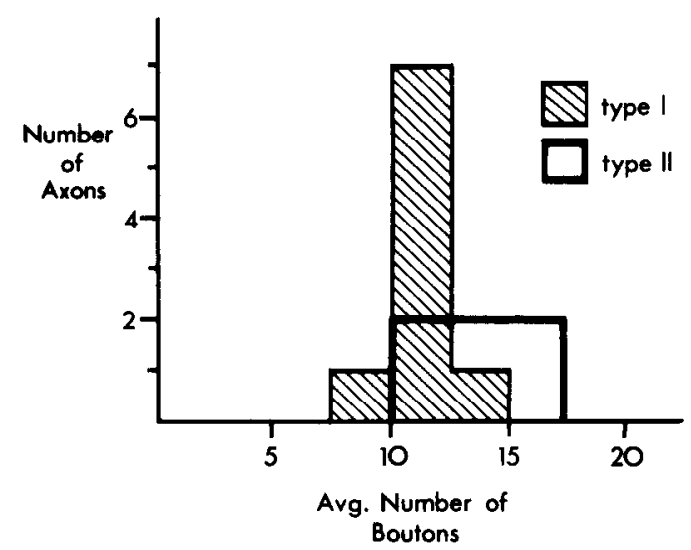

Figure 12. Bar graph illustrating the average number of boutons along a $50 \mu \mathrm{m}$ length of axon arbor for type I and type II axons. Type II axons have more boutons on average within a restricted length of axon than type I axons. 


\section{Type 1}
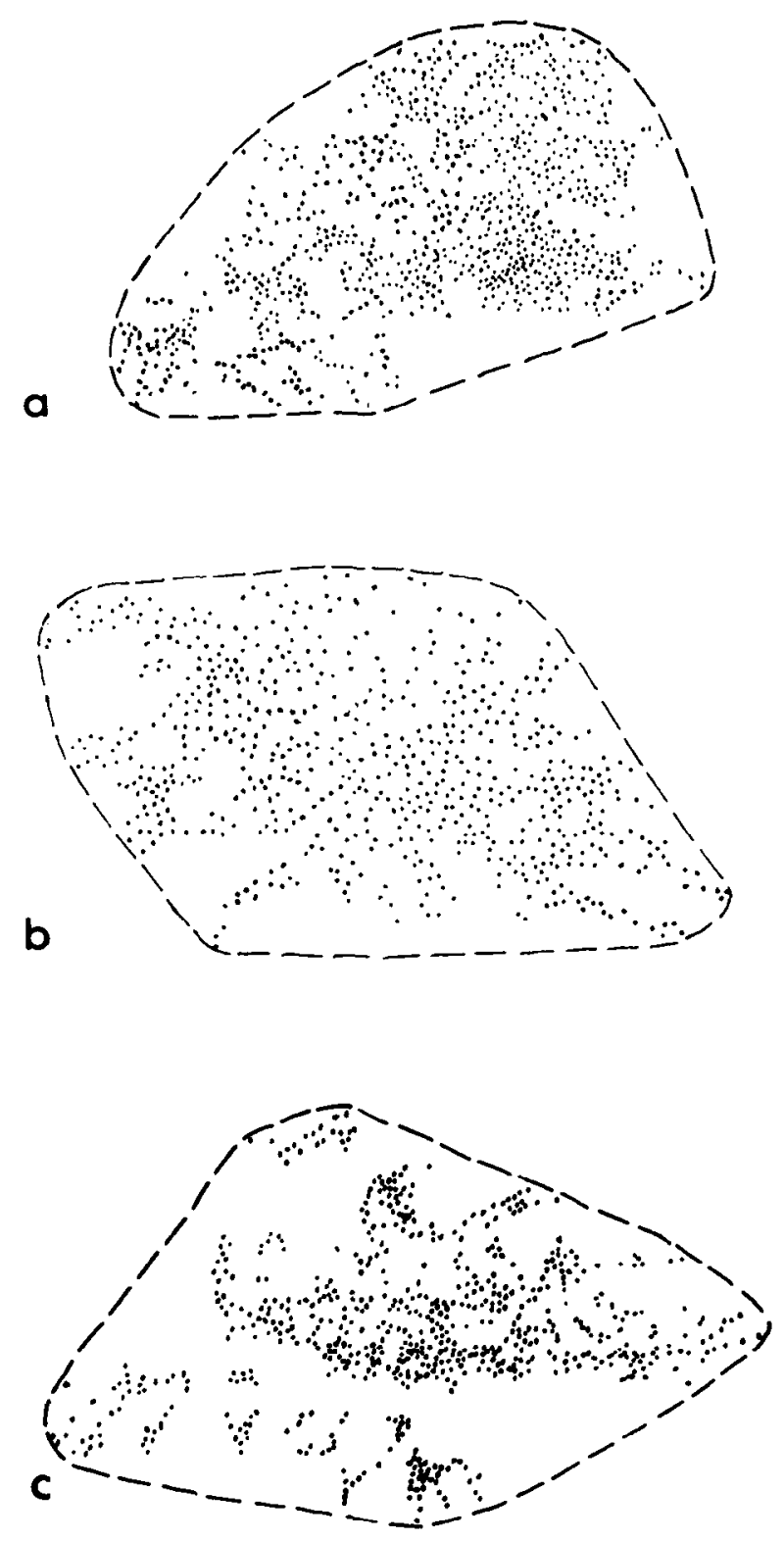

\section{Type II}

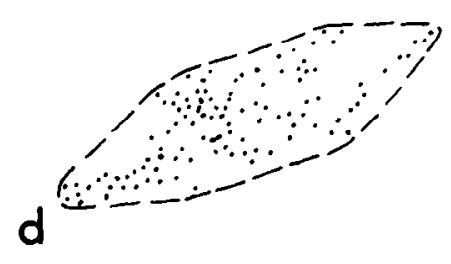

$\mathbf{e}$
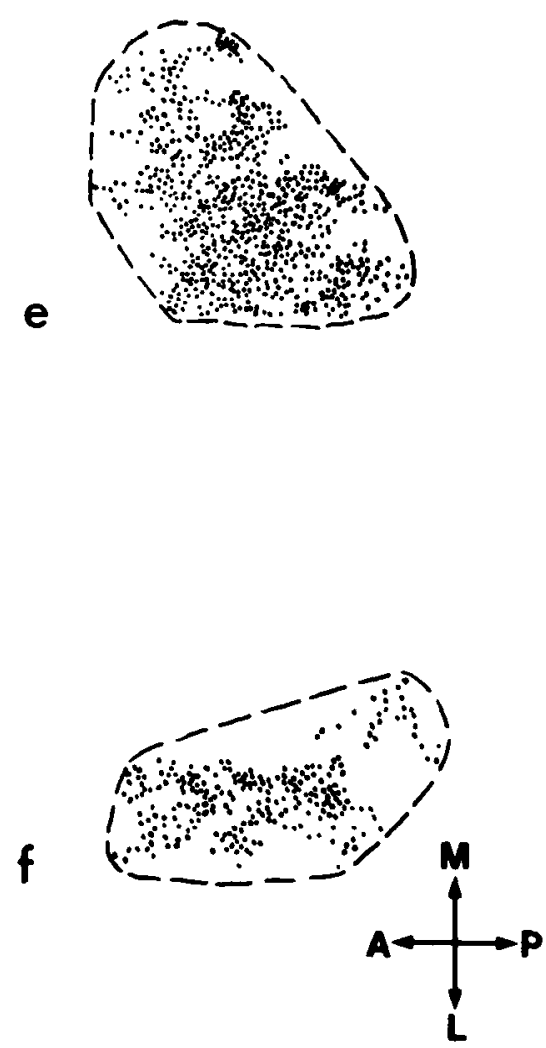

Figure 13. Dorsal reconstructions of the arrangement of boutons to demonstrate both the position of boutons within each terminal arborization and the shape of the arbor in a plane parallel to the pial surface. Reconstructions at left $(a-c)$ are from type I axons and at right $(d-f)$ are from type II axons. Note that, with the exception of $c$, boutons appear to be randomly positioned within the arbor. The dashed lines emphasize the elongated shape of most of the terminal arbors. $A$, anterior; $L$, lateral; $M$, medial; $P$, posterior.

gests that cortical cells lying in layer IVC $\alpha$ and IVC $\beta$ differ both in terms of physiological response profiles and anatomical connections. Blasdel and Fitzpatrick (1984) have recently shown that cells in IVC $\beta$ have smaller receptive fields and exhibit lower contrast sensitivities and higher acuities than cells in IVC $\alpha$. This is just what one would predict from differences in the physiological response properties of the inputs to these cells from parvocellular (X-like) and magnocellular (Y-like) LGN cells (Hicks et al., 1983; Derrington and Lennie, 1984; see however, Kaplan and Shapley, 1982). Since parvocellular and magnocellular LGN cells in galagos behave in a similar manner to their counterparts in macaque monkeys (Kuyk et al., 1983; Casagrande et al., 1986; Irvin et al., 1986; Norton et al., 1988), cells in striate cortical sublayers IV $\beta$ and IV $\alpha$ in galagos may show comparable physiological differences. In macaque monkeys, it has also been shown that cells in layer IVC $\alpha$, which receive input from magnocellular or Y-like LGN cells, send input to cells in layer IVB (Fitzpatrick et al., 1985). The layer IVB cells, in turn, send projections to visual cortical area MT of extrastriate cortex (Lund et al., 1975; Maunsell and Van Essen, 1983). In contrast, cells in layer IVC $\beta$, which receive input from parvocellular or X-like LGN cclls, send input to cells in layer IIIB and IVA (Fitzpatrick et al., 

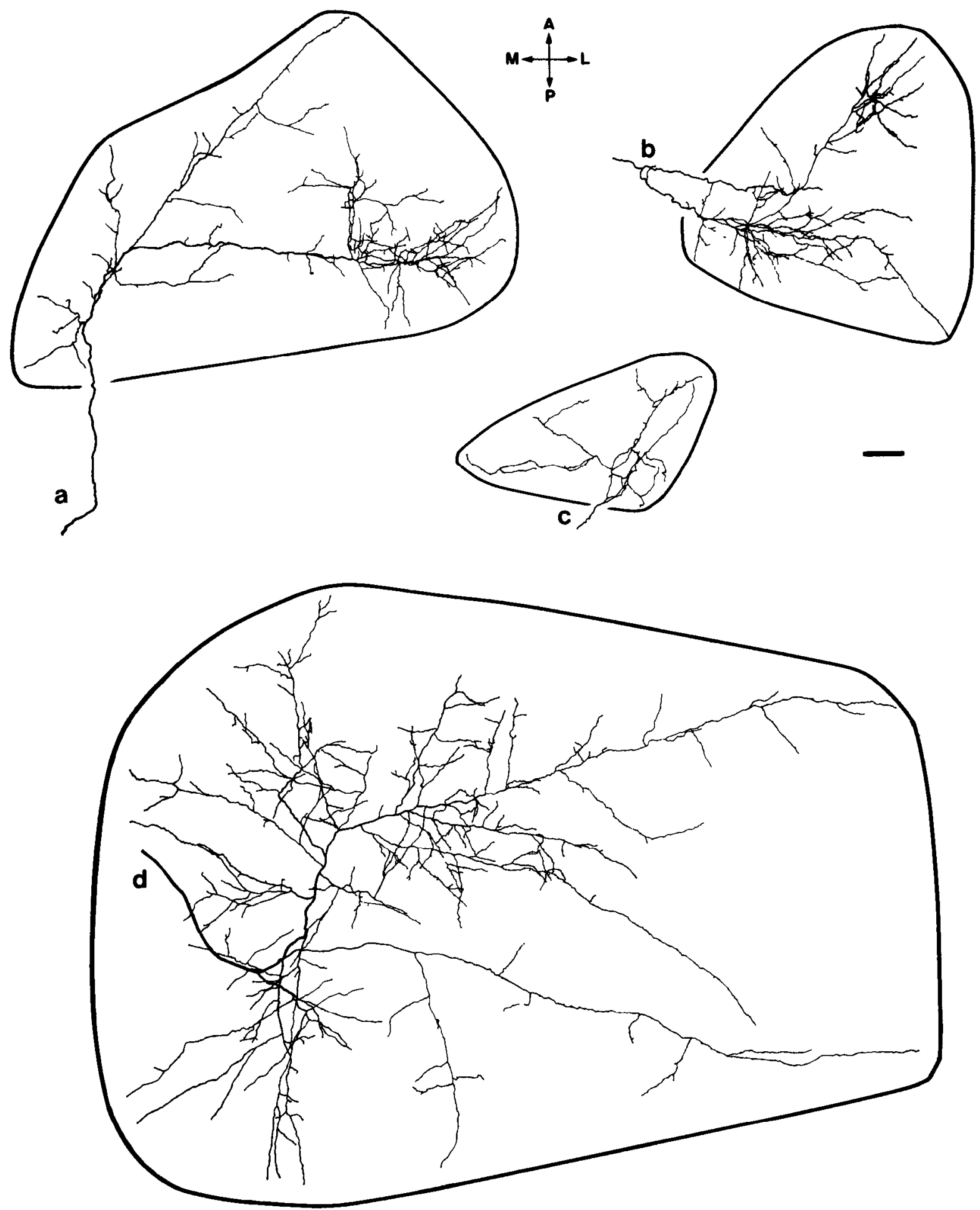

Figure 14. Reconstructions of afferent axons in layer IV from the striate cortex of a lesser galago in which the cortex had been unfolded, flattened, and sectioned parallel to the pial surface. This view illustrates the tangential spread of terminal arbors in layer IV. Because laminar borders are hard to define in the flattened sections, the axons have not been designated type I or type II. A solid line has been drawn around the most outlying branches of each arbor to highlight the shape of the terminal arbor. Notice that fibers shown in $a, c$, and $d$ are clearly elongate. $A$, anterior; $P$, posterior; $L$, lateral; $M$, medial. Scale bar, $50 \mu \mathrm{m}$.

1985). Cells in these layers send projections to area 18 via a relay through cortical layers II/IIIA (Lund et al., 1975; Rockland and Pandya, 1981). Since many of the same sets of connections with extrastriate cortex described in monkeys have been identified in galagos (Weller and Kaas, 1982), it follows that the differences we see in the morphology and distribution of axons in layer IV are important in maintaining the separate identities of 2 parallel streams of information.

We have thus far argued that the axons we describe belong to different subpopulations based upon their sublaminar distri- 
bution; however, our results also show that type I and II axons are morphologically quite distinct. Of these morphological distinctions, perhaps the most striking concerns their relative size differcnces. Type I axons radiate widely in IV $\alpha$ and are on average more than twice as large in areal extent compared to type II axons which terminate in restricted zones of IV $\beta$. Further, as mentioned in Results, small-caliber axons (such as those projecting to layers II and III) do not fill well with HRP, and it is possible that very small type II axons have been overlooked in this study. If this is the case, then the difference between type I and II axons in terminal arbor size may be even greater than shown in the present study.

Assuming that type I and type II axons originate from magnocellular and parvocellular LGN cells, respectively, this arrangement suggests that individual $Y$-like LGN cells are in a position to influence more cells in cortex than individual $\mathrm{X}$-like cells. However, the degree to which the relationships mentioned above translates into postsynaptic activity depends in a complex way on many other factors such as density, size, and position of synapses. Regardless, it remains the case that the $\mathrm{X}$ - and $Y$-like channels in galagos appear to be more in balance at the cortical level than at earlier stages of visual information processing, such as in the LGN where X-like cells outnumber Y-like cells almost 4 to 1 (Casagrande, unpublished results). Similar observations have been made concerning the relative balance of $\mathrm{X}$ or $\mathrm{X}$-like and $\mathrm{Y}$ or $\mathrm{Y}$-like channels at different levels of the geniculostriate system in cats and macaque monkeys (Fricdlander et al., 1981; Connolly and Van Essen, 1984; Freund et al., 1985; Humphrey et al., 1985).

Further clues as to the functional roles of these 2 geniculocortical pathways are provided by the differences in bouton number and in axon size between type I and type II fibers. Concerning bouton number, our results show that type II axons have significantly more boutons per linear extent of axon than type I axons. Since no other difference exists between type I and type II axons with respect to bouton size and arrangement, and assuming that bouton structure reflects the number of synapses within a bouton, then type II axon arbors likely make more synapses within a restricted cortical region than type I axon arbors (Winfield et al., 1982, 1983). It is unclear what a higher, local density of synapses might mean functionally for type II arbors, and without more information concerning either the overall number of boutons per unit cortical area (taking into account potential arbor overlap), it is difficult to speculate about the functional significance of these differences. However, speculations about the importance of axon size differences can be made. Since axon size correlates directly with axon conduction velocity, the type I axons presumably transmit information to cortex more rapidly than type II axons. In fact, it has been shown in galagos that Y-like LGN cells have significantly faster antidromic latencies from stimulation of striate cortex than X-like LGN cells (Norton and Casagrande, 1982; Irvin et al., 1986). More important, from a functional standpoint, is the fact that the latency to visual stimulation (both onset time and time to peak firing rate) is significantly faster for Y-like than for X-like LGN cells. This means that, given the shorter conduction times to cortex, type I (presumed $Y$-like) axons are in a position to transmit visual information to postsynaptic cells more rapidly than type II (presumed X-like) axons. These temporal differences are on the order of more than $10 \mathrm{msec}$ for latency to onset time and more than $40 \mathrm{msec}$ for latency to maximum firing (Kuyk et al., 1983; Irvin et al., 1986), and they must therefore

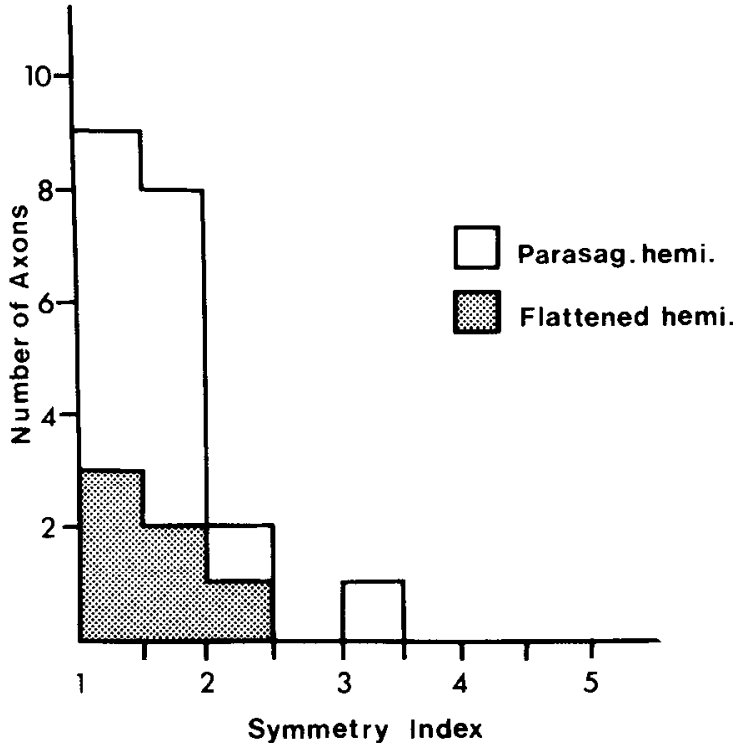

Figure 15. Bar graph of the symmetry indices of axonal arbors reconstructed from visual cortices that were either cut in a parasagittal plane or flattened and cut parallel to the pial surface. Note that the symmetry indices for the 2 samples overlap, suggesting that the elongation of the reconstructed arbors is not an artifact of the plane of section.

affect the manner in which information arriving via $\mathrm{Y}$-like or $\mathrm{X}$-like channels is eventually combined. How such differences relate to the importance of the Y-like channel in processing spatial or temporal information remains to be determined.

Arbor size and shape in relationship to cortical lopography

The terminal arbor size and shape of LGN axons must relate in an orderly manner to a number of parameters, including receptive field size, receptive field scatter, relative magnification of the visual field onto cortex, ocular dominance arrangements, and anisotropies contained within the map of the field. In galagos we do not have information on all of these parameters; however, what information we do have suggests the following relationships.

Our results are the first clear demonstration that arbors differ significantly in size with eccentricity; both arbor types are larger in cortex representing central vision (dorsal bank) than in cortex representing peripheral vision (calcarine fissure). This is most easily accounted for by the proportionally greater increase in the magnification of the representation of central vision over peripheral vision in galago striate cortex compared to the LGN (J. M. Allman, personal communication). This change in relative visual field magnification within the visual cortex would require $L G N$ axonal arbors representing $1^{\circ}$ of central visual space to communicate with a larger area of cortex than LGN axonal arbors representing $1^{\circ}$ of peripheral visual space.

Our data also provide evidence for a consistent elongation of terminal arbors. It is possible that the arbors are shaped by binocular competitive constraints during early development. In fact, Blasdel and Lund (1983) have shown that in monkeys a single axon in layer IVC $\alpha$ arborizes primarily with the ocular dominance columns innervated by the same eye. Although this hypothesis would fit well with data on type I arbors, it cannot account for the asymmetric shape of the type II arbors, many of which are smaller in diameter than the width of an ocular dominance column. Since other mechanisms obviously act to 

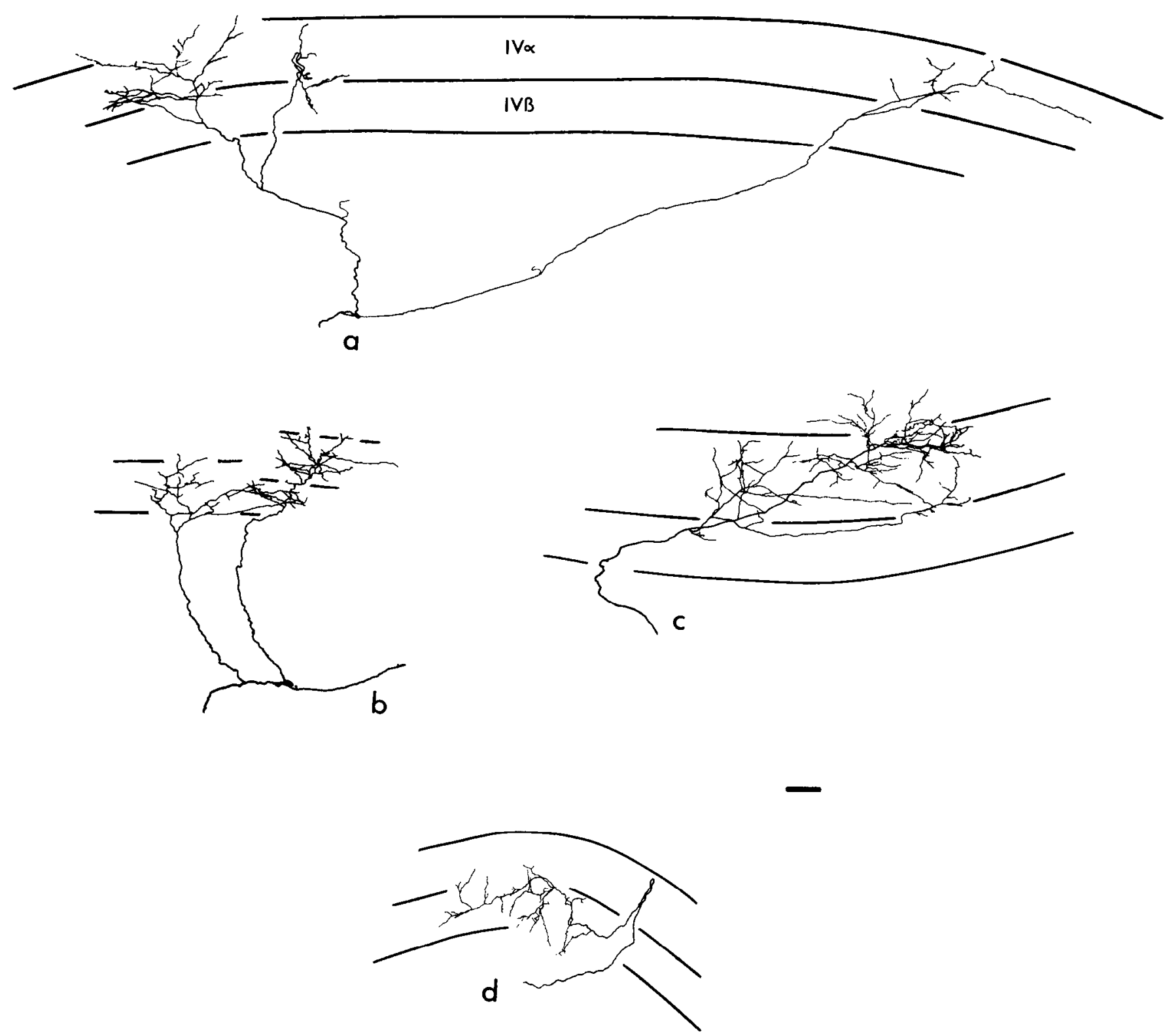

Figure 16. Composite of type I $(a-c)$ and type II $(d)$ fibers serially reconstructed from the striate cortices of greater galagos. In $a$ and $b$, reconstructions are shown of type I afferents that bifurcate and arborize in 2 discrete cortical loci. In $a$, the 2 terminal arbors are separated by $850 \mu \mathrm{m}$; in $b$, the 2 terminal arbors are separated by $240 \mu \mathrm{m}$. In $d$, the representation of the end of the axon (distal to the arborization) cannot be accurately reflected with respect to layer IV due to the sharp curvature of the cortex in the area where the axon is located. Scale bar, $50 \mu \mathrm{m}$.

restrict arbors topographically, it could be that the arbor elongation matches topographic anisotropies within cortex (Tootell et al., 1982; Van Essen et al., 1984) or is the outcome of mechanisms that allow different anisotropies within individual geniculate layer maps (see Connolly and Van Essen, 1984) to match within a single map in striate cortex.

\section{Comparison with work in cats and monkeys}

There have been a number of studies concerning the morphology of individual HRP-filled geniculostriate afferents in cats, and until recently it was thought that axons of LGN Y-cells ramified primarily in the upper tier of striate layer IV (IVab), while afferents from LGN X-cells ramified within the lower tier of IV (IVc) (Ferster and LeVay, 1978; Bullier and Henry, 1979; G.lbert and Wiesel, 1979; Humphrey et al., 1982). Recently, how- ever, it has been shown that the laminar segregation of individual $\mathrm{X}$ - and $\mathrm{Y}$-cell axons in striate cortex is not as clear as was previously believed. Instead, $X$-cell axon terminals are found throughout layer IV, sometimes filling the whole laminar width, and $Y$-cell afferents are either restricted to the upper tier of IV (as previously reported) or ramify uniformly throughout the layer (Freund et al., 1985; Humphrey et al., 1985). Despite the overlapping projection patterns of cat LGN X-and Y-cell axons, these axon types are still reported to differ from one another in terms of axon size and terminal arbor size; Y-cells have significantly larger axons and terminal arbors than X-like cells (Freund et al., 1985; Humphrey et al., 1985). In these latter respects, the $\mathrm{Y}$ - and X-cell terminal arbors resemble their type I and type II counterparts in galagos.

In macaque monkeys, the afferents from LGN X-like and 
Y-like cells in layer IV are strikingly similar to our type II (presumed X-like) and type I (presumed Y-like) afferents in galagos (Blasdel and Lund, 1983). As in galagos, Y- and X-like terminal arbors are spatially segregated in monkey cortex to layers IVC $\alpha$ and IVC $\beta$, respectively, and differ in terms of size and morphology.

The biggest difference between the LGN arbors of cats, monkeys, and galagos concerns their absolute sizes. According to Humphrey et al. (1985), the average size of X-cell terminal arbors in cats is $0.7 \mathrm{~mm}^{2}$, while $\mathrm{Y}$-cell terminal arbors average $1.3 \mathrm{~mm}^{2}$. The arbors from X-and Y-like LGN cells in monkeys and galagos are much smaller, averaging 0.07 and $0.5 \mathrm{~mm}^{2}$, respectively, in monkeys (see Humphrey et al., 1985, for mean values approximated from work of Blasdel and Lund), and 0.04 and $0.08 \mathrm{~mm}^{2}$, respectively, in lesser galagos. The species differences in the size of geniculostriate afferent arbors do not relate in any simple proportional way to cortical area since the average size of area 17 is $380 \mathrm{~mm}^{2}$ in cats (Tusa et al., 1977), $1269 \mathrm{~mm}^{2}$ in monkeys (Van Essen et al., 1984), and $56 \mathrm{~mm}^{2}$ in lesser galagos (unpublished observations). A more appropriate way to compare this information may be in terms of the average arbor size in relationship to the cortical point image, aggregate field, or spatial subunit size (Hubel and Weisel, 1974; Albus, 1975), defined as the product of the cortical magnification and aggregate field size (receptive field size plus scatter). For cats, it has been argued that this unit is about $5.0 \mathrm{~mm}^{2}$ (Albus, 1975), and for monkeys, about $3.1 \mathrm{~mm}^{2}$ (Hubel and Wiesel, 1974). If one assumes that in galagos the spatial subunit is very close in size to the cortical magnification factor for area centralis, as it is in cats, then the comparable value for galagos is $0.32 \mathrm{~mm}^{2}$. If one now compares the relative size of cortical $\mathrm{X}$ or $\mathrm{X}$-like arbors between species with their respective spatial subunits, cats and galagos are very similar, with around $1 / 7$ to $1 / 8$ of a spatial subunit occupied by one arbor, whereas in monkeys X-like arbors occupy only about $1 / 45$ of a spatial subunit. In contrast, comparison between the relative proportion of a spatial subunit occupied by a $Y$ or $Y$-like arbor is rather similar across species being $1 / 4$, $1 / 4$, and $1 / 6$ for cats, galagos, and monkeys, respectively. If $\mathrm{X}$ or $\mathrm{X}$-like arbors are responsible for providing information concerning visual detail, then these results fit well with behavior since the spatial acuity of galagos and cats is nearly identical, whereas the acuity of monkeys is several octaves better (Blake et al., 1974; De Valois et al., 1974; Langston et al., 1986; Bonds et al., 1987).

\section{References}

Adams, J. C. (1977) Technical consideration in the use of horseradish peroxidase as a neuronal marker. Neuroscience 2: 141-145.

Adams, J. C. (1981) Heavy metal intensification of DAB-based HRP reaction products. J. Histochem. Cytochem. 29: 775 .

Albus, K. (1975) A quantitative study of the projection area of the central and paracentral visual field in area 17 of the cat. I. The precision of the topography. Exp. Brain Res. 29: 159-179.

Benevento, L. A., and M. Rezak (1975) Extrageniculate projections to layers VI and I of striate cortex (area 17) in the rhesus monkey (Macaca mulatta). Brain Res. 96: 51-55.

Blake, R., S. J. Cool, and M. L. J. Crawford (1974) Visual resolution in the cat. Vision Res. 14: 1211-1217.

Blasdel, G. G., and D. Fitzpatrick (1984) Physiological organization of layer IV macaque striate cortex. J. Neurosci. 4: 880-896.

Blasdel, G. G., and J. S. Lund (1983) Termination of afferent axons in macaque striate cortex. J. Neurosci. 3: 1389-1413.

Blasdel, G. G., J. S. Lund, and D. Fitzpatrick (1985) Intrinsic connections of macaque striate cortex: Axonal projections of cells outside lamina 4C. J. Neurosci. 5: 3350-3369.
Bonds, A. B., V. A. Casagrande, T. T. Norton, and E. J. DeBruyn (1987) Visual resolution and sensitivity in a nocturnal primate (Galago) measured with visual evoked potentials. Vision Res. 27: 845-859.

Bowling, D. B., and C. R. Michael (1980) Projection patterns of single physiologically characterized optic tract fibers in cat. Nature $286: 899-$ 902.

Bowling, D. B., and C. R. Michael (1984) Terminal patterns of single physiologically characterized optic tract fibers in the cat's lateral geniculate nucleus. J. Neurosci. 4: 198-216.

Brodmann, K. (1909) Vergleichende Lokalisationslehre der Grosshirnrinde, Barth, Leipzig.

Bullier, J., and G. H. Henry (1979) Laminar distribution of first-order neurons and afferent terminals in cat striate cortex. J. Neurophysiol. 42: $1271-1281$.

Bullier, J., and T. Norton (1979) X and Y relay cells in cat lateral geniculate nucleus: Quantitative analysis of receptive-field properties and classification. J. Neurophysiol. 42: 244-273.

Carey, R. G., D. Fitzpatrick, and I. T. Diamond (1979) Layer I of striate cortex of Tupaia glis and Galago senegalensis: Projections from thalamus and claustrum revealed by retrograde transport of horseradish peroxidase. J. Comp. Neurol. 186: 393-438.

Casagrande, V.A., and E. J. DeBruyn (1982) The galago visual system: Aspects of normal organization and developmental plasticity. In The Lesser Bushbaby as an Animal Model: Selected Topics, D. Haines, ed., pp. 107-135, CRC Press, Boca Raton, FL.

Casagrande, V. A., and L. C. Skeen (1980) Organization of ocular dominance columns in galago demonstrated by autoradiographic and deoxyglucose methods. Soc. Neurosci. Abstr. 6: 315.

Casagrande, V. A., D. Raczkowski, and I. T. Diamond (1977) Effects of visual deprivation on the development of visual pathways in the galago. Soc. Neurosci. Abstr. 3: 555.

Casagrande, V. A., G. E. Irvin, T. T. Norton, M. A. Sesma, and H. M. Petry (1986) Difference of gaussians model of CSF's from W-, X-, and Y-like cells in primate LGN. Invest. Ophthalmol. Vis. Sci. Suppl. 27: 16.

Conley, M., E. Birecree, and V. A. Casagrande (1985) Neuronal classes and their relation to functional and laminar organization of the lateral geniculate nucleus: A Golgi study of the prosimian primate, Galago crassicaudatus. J. Comp. Neurol. 242: 561-583.

Connolly, M., and D. Van Essen (1984) The representation of the visual field in parvicellular and magnocellular layers of the lateral geniculate nucleus in the macaque monkey. J. Comp. Neurol. 226: 544-564.

Derrington, A. M., and P. Lennie (1984) Spatial and temporal contrast sensitivities of neurons in lateral geniculate nucleus of macaque. $J$. Physiol. (Lond.) 357: 219-240.

De Valois, R. L., H. Morgan, and D. M. Snoderly (1974) Psychological studies of monkey vision. III. Spatial luminance contrast sensitivity tests of macaque and human observers. Vision Res. 14: 75.

Diamond, I. T., M. Conley, K. Itoh, and D. Fitzpatrick (1985) Laminar organization of geniculocortical projections in Galago senegalensis and Aotus trivirgatus. J. Comp. Neurol. 242: 584-610.

Doty, R. W. (1983) Nongeniculate afferents to striate cortex in macaques. J. Comp. Neurol. 218: 159-173.

Dreher, B., Y. Fukuda, and R. W. Rodieck (1976) Identification, classification, and anatomical segregation of cells with $\mathrm{X}$-like and $\mathrm{Y}$-like properties in the lateral geniculate nucleus of Old-World primates. J. Physiol. (Lond.) 258: 433-452.

Ferster, D., and S. LeVay (1978) The axonal arborizations of lateral geniculate nucleus in the striate cortex of the cat. J. Comp. Neurol. 182: 923-944.

Fitzpatrick, D., K. Itoh, and I. T. Diamond (1983) The laminar organization of the lateral geniculate body and the striate cortex in the squirrel monkey (Saimiri sciureus). J. Neurosci. 3: 673-702.

Fitzpatrick, D., J. S. Lund, and G. G. Blasdel (1985) Intrinsic connections of macaque striate cortex: Afferent and efferent connections of lamina 4C. J. Neurosci. 5: 3329-3349.

Florence, S. L., M. A. Sesma, and V. A. Casagrande (1983) Morphology of geniculo-striate afferents in a prosimian primate. Brain Res. 270: 127-130.

Freund, T. F., K. A. C. Martin, and D. Whitteridge (1985) Innervation of cat visual areas 17 and 18 by physiologically identified $X-$ and Y-type thalamic afferents. I. Arborization patterns and quantitative distribution of postsynaptic elements. J. Comp. Neurol. 242: 263274. 
Friedlander, M. J., C.-S. Lin, and S. M. Sherman (1979) Structure of physiologically identified X-and Y-cells in the cat's lateral geniculate nucleus. Science 204: 1114-1117.

Friedlander, M. J., C.-S. Lin, L. R. Stanford, and S. M. Sherman (1981) Morphology of functionally identified neurons in the lateral geniculate nucleus of the cat. J. Neurophysiol. 46: 80-129.

Gilbert C. D., and T. N. Wiesel (1979) Morphology and intracortical projections of functionally characterized neurons in the cat visual cortex. Nature 280: 120-125.

Glendenning, K. K., E. A. Kofron, and I. T. Diamond (1976) Laminar organization of projections of the lateral geniculate nucleus to the striate cortex in galago. Brain Res. 105: 538-546.

Hässler, R. (1967) Comparative anatomy of central visual systems in day- and night-active primates. In Evolution of the Forebrain, R. Hässler and H. Stephen, eds., pp. 419-434, Plenum, New York.

Hayes, W. L. (1973) Statistics for the Social Science, Holt, Rinehart, and Winston, New York.

Hendrickson, A. E., J. R. Wilson, and M. D. Ogren (1978) The neuroanatomical organization of pathways between dorsal lateral geniculate nucleus and visual cortex in Old- and New-World primates. J. Comp. Neurol. 182: 123-136.

Hicks, T. P., B. B. Lee, and T. R. Vidyasagar (1983) The responses of cells in macaque lateral geniculate nucleus to sinusoidal gratings. J. Physiol. (Lond.) 337: 183-200.

Hubel, D. H., and T. N. Wiesel (1962) Receptive fields, binocular interaction and functional architecture in the cat's visual cortex. J. Physiol. (Lond.) 160: 106-154.

Hubel, D. H., and T. N. Wiesel (1968) Receptive fields and functional architecture of monkey striate cortex. J. Physiol. (Lond.) 195: 215273.

Hubel, D. H., and T. N. Wiesel (1972) Laminar and columnar distribution of geniculo-cortical fibers in macaque monkey. J. Comp. Neurol. 146: 421-450.

Hubel, D. H., and T. N. Wiesel (1974) Uniformity of monkey striate cortex: A parallel relationship between field size, scatter, and magnification factor. J. Comp. Neurol. 158: 295-306.

Hubel, D. H., and T. N. Wiesel (1977) Functional architecture of macaque monkey visual cortex. Proc. R. Soc. London [Biol.] 198: 1 59.

Humphrey, A. L., M. Sur, and S. M. Sherman (1982) Cortical axon terminal arborization and soma location of single functionally identified lateral geniculate nucleus neurons. Soc. Neurosci. Abstr. 8: 2.

Humphrey, A. L., M. Sur, D. J. Uhlrich, and S. M. Sherman (1985) Projection patterns of individual X-and Y-cell axons from the lateral geniculate nucleus to cortical area 17 in the cat. J. Comp. Neurol. 233: $159-189$.

Irvin, G. E., T. T. Norton, M. A. Sesma, and V. A. Casagrande (1986) W-like receptive-field properties of interlaminar zone cells in the lateral geniculate nucleus of a primate (Galago crassicaudatus). Brain Res. 362: 254-270.

Kaas, J. H. (1986) The structural basis for information processing in the primate visual system. In Visual Neuroscience, J. D. Pettigrew, W. R. Levick, and K. J. Sanderson, eds., pp. 315-340, Cambridge, UK.

Kaplan, E., and R. Shapley (1982) X-and Y-cells in the lateral geniculate nucleus of the macaque monkey. J. Physiol. (Lond.) 330: 125-143.

Kuyk, T. K., G. E. Irvin, H. M. Petry, V. A. Casagrande, and T. T. Norton (1983) Latencies to visual stimulation and spatial tuning in the primate X-like and Y-like LGN cells. Invest. Ophthalmol. Vis. Sci. Suppl. 24: 265.

Langston, A., V. A. Casagrande, and R. Fox (1986) Spatial resolution of the galago. Vision Res. 26: 791-796.

Lennie, P. (1980) Parallel visual pathways: A review. Vision Res. 20: 561-594.

LeVay, S., and H. Sherk (1981) The visual claustrum of the cat. I. Structure and connections. J. Neurosci. 1: 956-980.

Lund, J. S., R. D. Lund, A. E. Hendrickson, A. H. Bunt, and A. F. Fuchs (1975) The origin of efferent pathways from the primary visual cortex (area 17) of the macaque monkey as shown by retrograde transport of horseradish peroxidase. J. Comp. Neurol. 164: 287-304.

Maunsell, J. H. K., and D. C. Van Essen (1983) The connections of the middle temporal visual area (MT) and their relationship to a cortical hierarchy in the macaque monkey. J. Neurosci. 3:2563-2586.

Mason, C. A., and J. A. Robson (1979) Morphology of retino-geniculate axons in the cat. Neuroscience 4: 79-97.

Norton, T. T., and V. A. Casagrande (1982) Laminar organization of receptive-field properties in the lateral geniculate nucleus of bushbaby (Galago crassicaudatus). J. Neurophysiol. 47: 715-741.

Norton, T. T., V. A. Casagrande, G. E. Irvin, M. A. Sesma, and H. M. Petry (1988) Contrast sensitivity functions of $W_{-}, X-$, and $Y$-like relay cells in the lateral geniculate nucleus of the bush baby (Galago crassicaudatus). J. Neurophysiol. (in press).

Ogren, M. P., and A. E. Hendrickson (1978) The distribution of pulvinar terminals in visual areas 17 and 18 of the monkey. Brain Res. 137: 343-350.

Rezak, M., and L. A. Benevento (1979) A comparison of the organization of the projections of the dorsal lateral geniculate nucleus, the inferior pulvinar, and adjacent lateral pulvinar to primary visual cortex (area 17) in the macaque monkey. Brain Res. 167: 19-40.

Rockland, K. S., and D. N. Pandya (1979) Laminar origins and terminations of cortical connections of the occipital lobe in rhesus monkey. Brain Res. 179: 3-20.

Rockland, K. S., and D. N. Pandya (1981) Cortical connections of the occipital cortex in rhesus monkey: Interconnections between 17,18 , 19, and the superior temporal sulcus. Brain Res. 212: 249-270.

Spatz, W. B. (1977) Topographically organized reciprocal connections between areas 17 and MT (visual area of superior temporal sulcus) in the marmoset (Callithrix jacchus). Exp. Brain Res. 27: 559-572.

Stone, J., and B. Dreher (1982) Parallel processing of information in the visual pathways. A general principle of sensory coding? Trends in Neurosci. 441: 446.

Stone, J., B. Dreher, and A. G. Leventhal (1979) Hierarchical and parallel mechanisms in the organization of visual cortex. Brain Res. Rev. 1: 345-394.

Sur, M., and S. M. Sherman (1982) Retino-geniculate terminations in cats: Morphological differences between X- and Y-cell axons. Science 218: 389-391.

Sur, M., M. Esguerra, P. E. Garraghty, M. F. Kritzer, and S. M Sherman (1987) Morphology of physiologically identified retinogeniculate $X$ and Y-axons in the cat. J. Neurophysiol. 58: 1-31.

Tigges, J., M. Tigges, and A. Perachio (1977) Complementary laminar terminations of afferents to area 17 originating in area 18 and in the lateral geniculate nucleus in squirrel monkey. J. Comp. Neurol. 176: $87-100$.

Tigges, J., M. Tigges, N. A. Cross, R. L. McBride, W. D. Letbetter, and S. Anschel (1982) Subcortical structures projecting to visual cortical areas in squirrel monkey (Saimiri). J. Comp. Neurol. 209: 29-40.

Tootell, R. B. H., M. S. Silverman, E. Switkes, and R. L. De Valois (1982) Deoxyglucose analysis of retinotopic organization in primate striate cortex. Science 218: 902-904.

Tusa, R. J., L. A. Palmer, and A. C. Rosenquist (1977) The retinotopic organization of area 17 (striate cortex) in the cat. J. Comp. Neurol. 177: 213-236.

Van Essen, D. C., and J. H. R. Maunsell (1980) Two-dimensional maps of the cerebral cortex. J. Comp. Neurol. 191: 255-281.

Van Essen, D. C., W. T. Newsome, and J. H. R. Maunsell (1984) The visual field representation in striate cortex of the macaque monkey: Asymmetries, anisotropies and individual variability. Vision Res. 24: 429-448.

Weber, J. T., M. F. Huerta, J. K. Kaas, and J. K. Harting (1983) The projections of the lateral geniculate nucleus of the squirrel monkey: Studies of the interlaminar zones and the S layers. J. Comp. Neurol. 213: 135-145.

Weller, R. E., and J. H. Kaas (1982) The organization of the visual system in galago: Comparisons with monkey. In The Lesser Bushbaby as an Animal Model, D. Haines, ed., pp. 108-135, CRC Press, Boca Raton, FL.

Winfield, D. A., and T. P. S. Powell (1983) Laminar cell counts and geniculocortical boutons in area 17 of cat and monkey. Brain Res. 277: 223-229.

Winfield, D. A., M. Rivera-Dominque, and T. P. S. Powell (1982) The termination of geniculo-cortical fibers in area 17 of the visual cortex of the macaque monkey. Brain Res. 231: 19-32. 